\title{
Measurement of Optical Properties of Fruits and Vegetables: A Review
}

\author{
Renfu $\mathrm{Lu}^{1, *}$, Robbe Van Beers ${ }^{2}$, Wouter Saeys ${ }^{2}$, Changying $\mathrm{Li}^{3}$, Haiyan Cen ${ }^{4}$
}

${ }^{1}$ U.S. Department of Agriculture Agricultural Research Service, East Lansing, Michigan, USA

${ }^{2}$ KU Leuven, Department of Biosystems, MeBioS, Kasteelpark Arenberg 30, 3001, Leuven, Belgium

${ }^{3}$ College of Engineering, University of Georgia, Athens, Georgia, USA

${ }^{4}$ College of Biosystems Engineering and Food Science, Zhejiang University, Hangzhou, China

* To whom corresponding should be sent. Email: renfu.lu@usda.gov (R. Lu)

Abstract

This paper provides an overview of the principles and theory of measuring optical properties of biological materials. It then presents the instrumentation and data analysis procedures for implementing several emerging optical techniques, including spatially resolved, time-resolved, and spatial-frequency domain, along with the standard integrating sphere method. Applications of these techniques for optical property measurement, maturity and quality assessment, and defect detection of fruits and vegetables are then reviewed, followed with discussions on issues and challenges that still need to be addressed for these emerging optical techniques. While these optical techniques are overall more sophisticated in instrumentation and computation, they are based on solid radiative transfer theory or diffusion approximation theory. Hence, measurement of optical absorption and scattering properties has the potential of providing more complete, objective information for quality evaluation of horticultural products. At present, these techniques are still slow in measurement, and prone to errors due to modeling and instrumentation deficiencies. Further research is therefore needed in using a better mathematical 
modeling approach, improving data acquisition accuracy and speed, and developing more robust

27 inverse algorithms for optical property estimations.

fruit, vegetable.

\section{Introduction}

Optical imaging and spectroscopic techniques now are widely used for property, quality and safety assessment of horticultural and food products. Most of these techniques rely on measurement and direct analysis of the output optical signals (i.e., spectra and/or images in the form of reflection or transmittance) acquired from food samples under a specific form of lighting

37 (i.e., diffuse or uniform lighting, point lighting, patterned lighting, etc.). This type of approach, which may be termed the direct approach, overall is simpler, faster and easier to implement for online or offline applications, compared to the optical measuring methods reviewed in this paper, which belong to the inverse or indirect approach. Conventional visible and near-infrared

41 (Vis/NIR) spectroscopy employs the direct approach to measure the aggregate amount of light 42 either reflected from or transmitted through a biological or food material, resulting from the combined effect of absorption and scattering of photons by the tissues. The acquired spectral

44 data are then processed, via mathematical techniques, for establishing a quantitative or qualitative relationship with the property or quality parameter(s) of interest. Once the calibration

46 model is established and validated, it can then be used for predicting new samples. There are,

47 however, some inherent shortcomings with conventional Vis/NIR technique and the direct 
49 phenomenological values (like force and pressure in mechanical measurements), and they are

50 influenced by such factors as type of instrument, sensing mode (reflectance, transmittance, etc.),

51 and light source/detecting probe setup. It thus presents great challenges in transferring the

52 Vis/NIR calibration models between different instruments or comparing the performance of

53 different instruments.

54 In recognizing the shortcomings or limitations of conventional Vis/NIR technique or the

55 direct approach in general, researchers have long sought alternative approaches to measure

56 optical absorption and scattering properties of food and biological materials. They are two

57 intrinsic material properties that characterize the behavior of light interaction with biological

58 tissues. Hence, the measured values for the two optical property parameters are, in principle,

59 independent of instrumentation type and lighting/detecting probe setup, which would make it

60 easier to compare the data acquired from different instruments for different studies. In this paper,

61 the terms 'optical properties' and 'bulk optical properties' are used interchangeably, both

62 referring to the average effect of different optical processes occurring in tissues at the

63 microscale. The light interaction with tissues can be described withtwo optical parameters related

64 to the two basic processes, i.e., absorption and scattering. Absorption is largely determined by

65 the chemical composition of the tissue, while scattering is dependent on density and tissue

66 structures (e.g., particle size, distributions, etc.). Hence, measurement of the two optical

67 parameters could provide more complete, objective information about the structural and

68 chemical properties of samples.

Early efforts had been made by Birth and colleagues in the late 1970s and early 1980s on

70 measuring the optical absorption and scattering properties of food products, based on the

71 empirical model (i.e., Kubelka-Munk model) for two-dimensional turbid slabs (Birth, 1978, 
72 1982; Birth et al., 1978). However, due to the limitations of optical and computer technologies

73 available at that time, the measurement procedure, which involved both reflectance and

74 transmittance, was quite tedious and time consuming. Nevertheless, these early studies provided

75 an alternative approach for optical property measurement, and they also demonstrated some

76 merits of using optical absorption and scattering parameters for assessing properties and quality

77 attributes of food products.

From the late1980s to the 2000s, rapid advances were made in Vis/NIR technique in both

79 hardware and software (i.e., chemometrics). A large variety of Vis/NIR instruments became

80 available, from expensive benchtop instruments to low-cost, miniaturized handheld devices.

81 Chemometric techniques also evolved from conventional linear modeling to nonlinear modeling

82 and to artificial neural networks. Thanks to these developments, Vis/NIR spectroscopy has

83 spread into different areas of food and agriculture applications as well as many other industries

84 (e.g., pharmaceutical and chemical), as shown by the exponential increase in scientific

85 publications over that period of time (Nicolaï et al., 2007). In comparison, little progress was

86 made on optical property measurement of food and agricultural products in the 1990s, with only

87 a few, sporadic scientific publications. However, the situation was completely different in

88 biomedical optics research. Since the mid-1980s, significant advances have been made in

89 noninvasive (also called in vivo in the biomedical optics field) techniques for measuring optical

90 absorption and scattering properties of biological materials, thanks to major breakthroughs in

91 analytical solutions to the theory of light transfer as well as optical detection and laser

92 technologies. Specifically, analytical solutions to the diffusion approximation theory, a

93 simplification to the radiative transfer theory, became available for several special, important

94 illumination conditions (i.e., steady-state or continuous-wave point lighting, pulsed point- 
lighting and frequency modulated lighting) (Farrell et al., 1992; Kienle and Patterson, 1997; Patterson et al., 1989, 1991). Based on these analytical models, several new techniques, including spatially resolved (SR), time-resolved (TR) and frequency-domain (FD), were developed for measuring optical properties of biological materials during the 1990s and 2000s (Tuchin, 2007).

The interest in these emerging optical property measurement techniques for food and agricultural products began to grow from the early 2000s, owing to the availability of more affordable optical instrumentation. TR technique was first applied to measure the optical properties of apples and other fruits (Cubeddu et al., 2001a, 2001b). Subsequently, a series of studies were reported by a group of researchers in Italy (Rizzolo and Vanoli, 2016) on using different TR instrumentation configurations (i.e., single wavelength, multi-wavelength and broad spectral region) to assess quality, maturity and internal defects of fruits and vegetables. Around that time period, several research groups in the U.S. and Europe also started to actively pursue SR techniques for measuring optical properties of fruits, vegetables and other food products. Researchers with the U.S. Department of Agriculture Agricultural Research Service (USDA/ARS) at Michigan State University in Michigan, USA developed a hyperspectral imaging-based SR technique for fast measurement of optical absorption and scattering properties of horticultural and food products over a broad range of wavelengths (Cen and Lu, 2010; Qin and Lu, 2007, 2008). Researchers at the University of Missouri, Columbia, Missouri, USA developed a SR technique, based on single-fiber spectroscopy, for measuring optical properties of meat muscles and meat analogs (Xia et al., 2007, 2008). Researchers from KU Leuven in Belgium, used the integrating sphere method (IS), coupled with an inverse adding-doubling (IAD) algorithm (hereinafter called IS-IAD), to measure the optical properties of apple, potato, 
118 and meat tissue components (López-Maestresalas et al., 2015; Saeys et al., 2008; Van Beers et 119 al., 2017b; Zamora-Rojas et al., 2013). Later, the group also developed other SR sensing 120 systems, based on single-fiber, multi-fiber and imaging-based configurations, for measuring 121 fruits and food products (Aernouts et al., 2015; Nguyen Do Trong et al., 2014a, 2014b; Van 122 Beers et al., 2015). More recently, researchers from the University of Georgia at Athens, 123 Georgia, USA used IS-IAD to measure optical properties of onions and other horticultural 124 products (Wang and Li, 2013, 2014; Zhang et al., 2019).

125 In recent years, new optical property measurement techniques have continued to emerge in 126 the biomedical optics field. Researchers from the University of California at Irvine, USA 127 reported on a new spatial-frequency domain (SFD) technique for wide-area imaging of the 128 optical properties of biological tissues (Cuccia et al., 2005). The SFD technique was used to 129 detect healthy and bruised apple tissues (Anderson et al., 2007). Recently, researchers at 130 Zhejiang University, Hangzhou, China and the USDA/ARS laboratory in Michigan, USA, used 131 SFD technique to measure optical properties of fruits and food products composed of one or two 132 homogeneous layers (Hu et al., 2016, 2018).

This paper is therefore intended to give an overview of the principles, theory and modeling of 134 light transfer in biological materials, followed by a brief introduction to the instrumentation and 135 data analysis approaches for IS-IAD, SR, SFD, and TR techniques. Applications of these 136 techniques for quality assessment of fruits and vegetables are then reviewed. Finally, discussions 137 are given on critical issues, challenges and future research needs for these techniques. This 138 review is aimed to help researchers and practitioners gain a better understanding of these 139 emerging optical property measurement techniques and their advantages and limitations, thus 140 stimulating further research in optical property measurement of horticultural and food products. 


\section{Principles and Theory of Light Transfer}

142

144

145

146

147

148

149

150

151

152

153

154

155

156

157

158

159

160

161

162

163

\subsection{Light transfer in biological materials}

Biological or plant tissues are a complex system formed by cells and their extracellular matrix. These cells and extracellular matrix contain different components like membranes, cytoskeletons, organelles, etc., each of which has different structural, chemical and optical characteristics. Hence, the actual process of light interaction with the biological tissue system is rather complex at the microscale. However, in studying light transfer in biological or plant tissues, they may be treated as being primarily composed of scattering (e.g., the organelles and cellular membranes) and absorbing (e.g., chromophores) particles. Under this simplified treatment, light transfer in biological tissues mainly involves the process of photon interactions with the scattering and absorbing particles. As photons enter the plant tissues, they will move straightforward until encountering a scattering or absorbing particle. The photons will change the travelling direction (called scattering) upon hitting the scattering particle, or they would be absorbed, if the particle is an absorbing particle and when the level of energy for the photons matches that of the particle according to quantum theory. The actual change in the scattering direction of the photons depends on the optical properties of the scattering particle. After the particle is hit by a large quantity of photons, the angular scattering profile can be described by the scattering phase function [designated as $p(\theta)$ ], which is unique for each particle and is determined by the size, shape and orientation of the particle. Specifically, the fraction of photons that would be scattered to a specific direction is determined by the anisotropy factor, designated as $g$. Values of $g$ range between -1 and 1 , where $g=-1$ is total backward scattering; $g=0$ is isotropic scattering (i.e., photons scatter equally in all directions), and $g=1$ represents total forward scattering. For most food and plant materials, $g$ values range between 0.7 and 0.9 , 
164 indicating that forward scattering is dominant. The absorption process can be characterized by

165 the absorption coefficient, normally designated as $\mu_{a}$. On the other hand, the scattering process is

166 defined by the scattering coefficient $\left(\mu_{s}\right)$ and the anisotropy factor $(g)$. Hence, with the

167 knowledge of $\mu_{a}, \mu_{s}$ and $g$, one can, in principle, describe the transfer of photons in biological

168 tissues. As shown in the following section, when scattering is dominant (i.e., $\mu_{s} \gg \mu_{a}$ ), the

169 anisotropy factor can be lumped into the scattering coefficient, which leads to a new optical

170 parameter, called the reduced scattering coefficient $\left[\right.$ i.e., $\mu_{s}^{\prime} \equiv(1-g) \mu_{s}$. This means that for most

171 plant materials like fruits and vegetables, it would be sufficient to use $\mu_{a}$ and $\mu_{s}$ for

172 characterizing the interaction of light with the plant material.

\subsection{Diffusion approximation theory}

174

175

176

177

178

179

180

181

182

183

184

The transfer of light in biological materials is best described by radiative transfer theory. The radiative transfer equation can be derived by employing the principle of conservation of energy. A detailed description on the derivation of the radiative transfer equation can be found in $\mathrm{Lu}$ (2016). Since the radiative transfer equation is expressed in an integro-differential form with six variables, it cannot be solved analytically, except for a few special, restricted situations.

Subsequently, the assumption of dominant scattering in turbid biological materials is used to approximate it as by a diffusion equation:

$$
\frac{\partial \Phi(\vec{r}, t)}{\partial t}=\nabla \cdot[D \nabla \Phi(\vec{r}, t)]-\mu_{a} \Phi(\vec{r}, t)+S(\vec{r}, t)
$$

where $\Phi(\vec{r}, t)$ is the fluence rate, $\vec{r}$ is the location vector, $t$ is the time variable, $S(\vec{r}, t)$ is the isotropic source in the medium, and $D$ is called the diffusion coefficient, which is given by

$$
D=\frac{1}{3\left[\mu_{a}+(1-g) \mu_{s}\right]}=\frac{1}{3\left(\mu_{a}+\mu_{s}^{\prime}\right)}
$$

where $\mu_{s}{ }^{\prime}$ is the reduced scattering coefficient. The diffusion equation only contains two 
186 independent optical parameters, i.e., the absorption and reduced scattering coefficients, and it has 187 been solved analytically for several special, important illumination situations, as shown in Figure 188 1, which include continuous-wave or steady-state point lighting (Figure 1a), pulsed point lighting 189 (Figure 1b), frequency-modulated point lighting (Figure 1c), and spatially-modulated area 190 lighting (Figure 1d) (Lu, 2016). These analytical solutions form the theoretical basis for the SR, 191 TS, FD, and SFD techniques described in Section 3.

Intensity



193

194

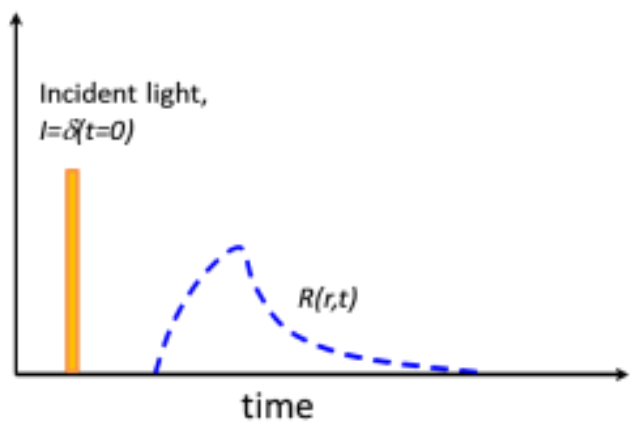

(a)
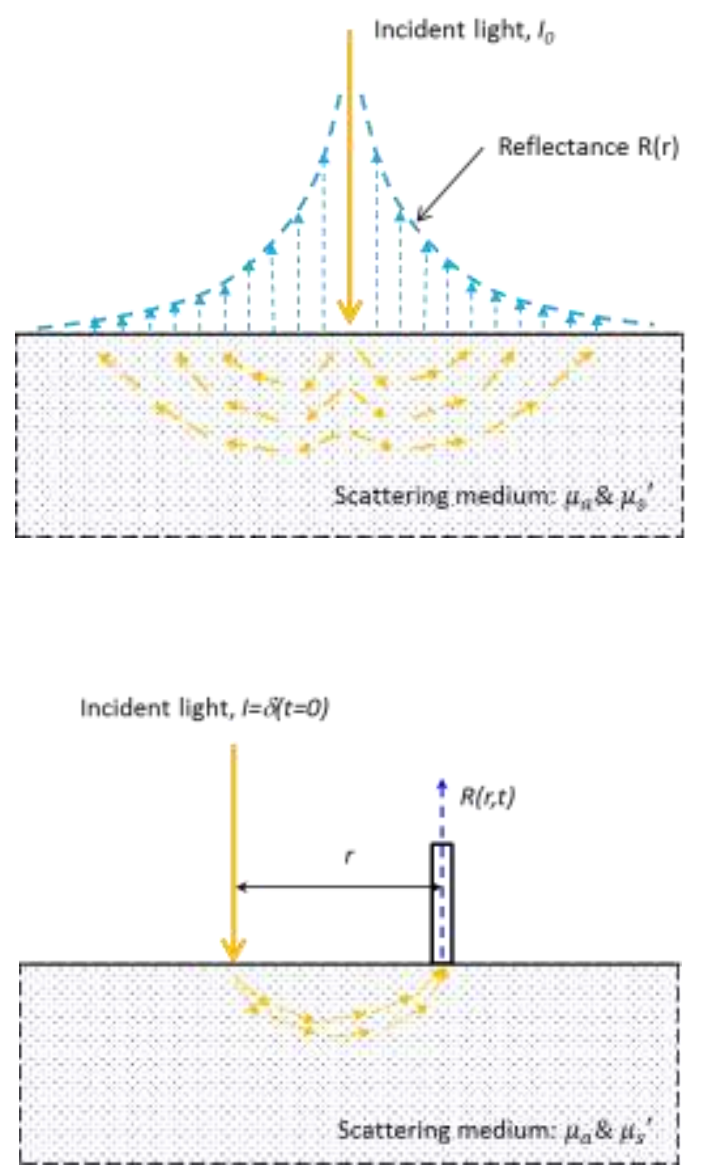
Incident light,

$I(t)=I_{0}\left[M_{0}+\sin (2 \pi f t)\right]$

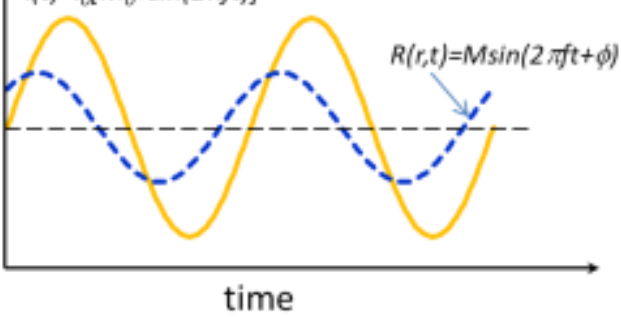

197 symbol $I$ represents the intensity of the incident light, $f$ is the frequency either in the time $(t)$ or spatial domain. It should be noted that in cases a) through c), the spatial dimensions are expressed in the two-dimensional polar coordinate system, while in case d), they are in the twodimensional Cartesian coordinate system.

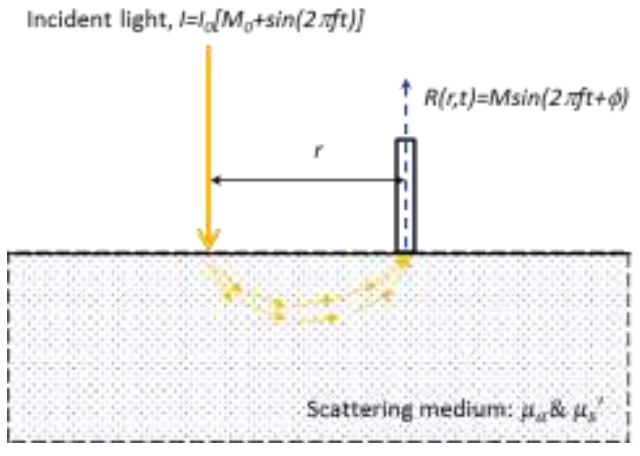

(c)

Incident Light: $I(x)=I_{0}\left[a_{0}+\sin (2 \pi f x+\alpha)\right]$

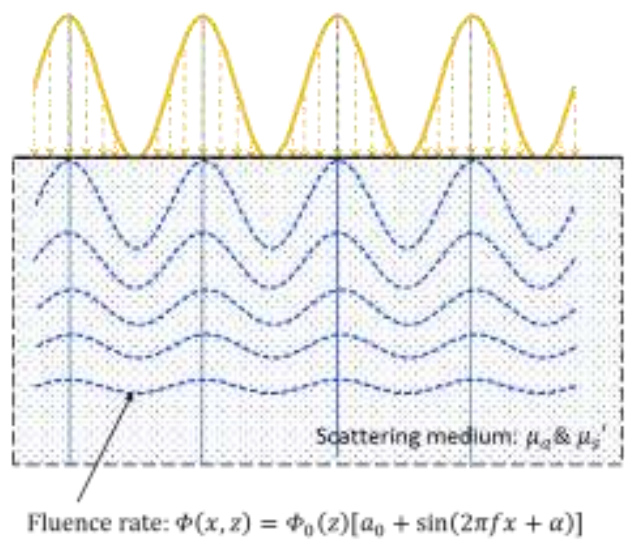

(d)
Figure 1. Four special cases of light illumination at the surface of a semi-infinite turbid medium, for which analytical solutions to the diffusion approximation equation are available: a) continuous-wave point lighting (time-independent), b) short-pulsed lighting, c) frequencymodulated point lighting, and d) spatially-modulated area lighting (time-independent), where 


\subsection{Numerical simulations}

Although the diffusion equation is widely used with SR, SFD and TR/FD techniques for estimating optical properties of biological materials, it is only applicable when scattering is dominant over absorption $\left(\mu_{s} \gg>\mu_{a}\right)$ and if the radiance is only considered at a sufficiently large distance from the point of illumination (>> one mean free path) (Martelli et al., 2010). In the Vis/NIR region of the spectrum, these assumptions do not always hold for biological tissues, due to the high absorption by biological chromophores, of which chlorophyll, carotenoids, anthocyanins and water are dominant in plant materials. To overcome these limitation researchers have used numerical methods, such as adding-doubling (AD) and Monte Carlo (MC) methods, to simulate light propagation in biological tissues (Prahl et al., 1993; Simpson et al., 2001; Tuchin, 2017; Wang et al., 1995).

The AD method, which was first introduced by van de Hulst (1980), is used to numerically solve the radiative transfer theory (RTT) for an infinitely thin and single-scattering homogeneous layer by calculating the angle-dependent reflection and transmission of that layer (Prahl, et al., 1993). With the assumption of single scattering, the RTT can be solved with relative ease for a series of bulk optical properties (BOP) (i.e., $\mu_{a}, \mu_{s}$, and $p(\theta)$ ). By adding layers with different optical properties, dissimilar slabs with internal reflections at the boundaries can be accounted for. Likewise, the differences in refractive indices $n$ between two materials, causing refraction and reflection at the boundaries, can be accounted for, respectively, using Snell's and Fresnel's laws. Eventually, for a specific sample slab, the AD routine results in angular reflectance and transmittance functions per wavelength. Integrating these functions over the different conical segments provides the total reflectance and total transmittance of the sample slab. The equations and algorithm of the AD method have been described in Prahl (1995). The AD approach is fast 
233 and accurate, but it is restricted to layered geometries and cannot be used to retrieve information

234 on the spatial distribution of the reflected and transmitted photons (Aernouts et al., 2014).

235 Moreover, each layer should have homogeneous BOP. The routine has been extended to estimate

236 the spectral and angular distribution of the scattered radiation of (fluorescent) materials (Leyre et

237 al., 2012), while it can also be inverted to retrieve the BOP for thin sample slabs from the

238 measured total transmittance and total reflectance, as described in Section 3.1 (Aernouts et al.,

239 2013; Prahl et al., 1993).

240

MC simulation is widely used for modeling light propagation in turbid biological tissues,

241 owing to its flexibility and simplicity in simulating the energy transfer process in arbitrary

242 geometries with complex boundary conditions or spatial localization of inhomogeneities. MC

243 methods provide a probabilistic approach to simulate the random walk of photons in absorbing

244 and scattering media (Watté et al., 2016). Photons are traced through a turbid medium until they

245 exit at the sample surface or until they are absorbed. Photon movement from one photon-tissue

246 interaction to the next is described by probability functions using the tissue's optical properties.

247 Repeating this process for a large number of photons results in an estimation of photon

248 distributions in the tissue (Wang and Jacques, 2000). Classic MC algorithms, such as the MC

249 code for multi-layered media, allow to simulate light propagation in multi-layered, semi-infinite

250 slabs (Wang et al., 1995). Moreover, the MC method can also be used in a structured finite mesh

251 approach, in which photons move in a tetrahedral mesh (Watté et al., 2015a). This approach

252 allows to describe more complex biological structures, including targets with curved boundaries

253 or locally refined structures, like tissue cells and intercellular spaces. Finally, meshless

254 approaches can be studied using particle-based simulations, in which photons and scattering

255 particles are defined as particles, while the interaction of light with spherical scattering particles 
can be determined using the exact Mie solution. However, because of the large number of photons (typically $10^{4}$ to $10^{6}$ ) that need to be simulated to reduce the effects of stochastic noise, MC simulations are generally computationally intensive (Tuchin, 2007).

To overcome some shortcomings of the previously described MC techniques (e.g., long computational time and oversimplifications in describing the photon-particle interactions) and to better deal with noise, which is inherently present when modelling data retrieved from optical measurements, stochastic data-based surrogate models, often referred to as 'metamodels', have been introduced as a computationally cost-effective alternative for solving the RTT for light propagation (Aernouts et al., 2015; Watté et al., 2013). These metamodels directly establish the link between the design space (input parameters) and the performance space (output parameters) (Simpson et al., 2001). These models would be trained by using the data obtained from MC simulations or optical measurements on samples with known BOP. Building a metamodel based on MC simulations would provide high flexibility. However, the estimation procedure can be simplified by linking optical measurements on known samples directly with the BOP. This has the advantage that in future predictions, using the same optical measurement technique, both light propagation characteristics and measurement geometry used are accounted for (Watté et al., 2013). To achieve this goal, so-called optical phantoms, designed with known optical properties, are measured with the same optical setup as that used for the actual measurements on the desired products. By doing this, a possible mismatch between simulation and measurement setup can be avoided. To use these phantom measurements for building a metamodel, a set of phantoms describing a wide range of absorption and scattering properties should be designed so that they are representative for the BOP of the measured products. Three different key components should be considered when designing optical phantoms: (1) the matrix material, (2) the type of absorber 
279 and (3) the scattering agent (Pogue and Patterson, 2006). The phantom ingredients should be

280 chosen carefully to avoid interactions between the components, as these might affect the

281 estimation of the BOP.

An example of creating a set of liquid optical phantoms by combining Naphthol Blue Black

283 (NBB) as an absorber (peak absorption at $618 \mathrm{~nm}$ ) and Intralipid ${ }^{\circledR} 20 \%$ as a scattering agent, is

284 shown in Figure 2. The rows (from number 1 to 7 ) have an increasing level of absorption, while

285 the columns (from letter B to $\mathrm{H}$ ) have an increasing level of scattering. The reference BOP

286 values, measured using a double integrating sphere (DIS) setup (Aernouts et al., 2013), served as

287 an input for building a forward metamodel, linking bulk optical properties to the diffuse

288 reflectance values at different distances from the point of illumination. The diffuse reflectance

289 was measured using a contactless hyperspectral scatter imaging setup.

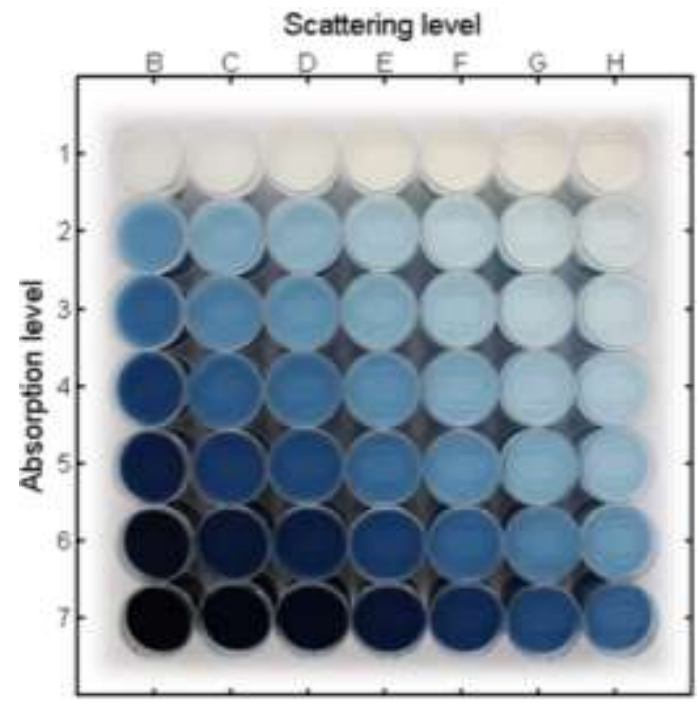

291 Figure 2. Set of 49 calibration phantoms made by combining Intralipid $^{\circledR} 20 \%$ (IL) as a

292 scattering agent, Naphthol Blue Black (NBB) as an absorber and water as a dilution agent.

293 The concentration of IL increases from left to right (level B to H), while the concentration

294 of NBB increases from top to bottom (level 1 to 7 ). 
A metamodel combining 30 source-detector distances was evaluated using a set of validation phantoms. The performance of the metamodel for the BOP estimations of 8 validation phantoms 297 at 91 different wavelengths (from $550 \mathrm{~nm}$ to $1000 \mathrm{~nm}$ in steps of $5 \mathrm{~nm}$ ) is illustrated in Figure 3.

298 The bulk absorption coefficient was predicted with an $\mathrm{R}^{2}$ of 0.998 and a root mean squared error 299 for validation (RMSE) of $0.200 \mathrm{~cm}^{-1}$ (Figure 3a), which are in agreement with the results 300 reported by Watté et al. (2015b), when a translation-stage SR setup was employed. Predicted 301 values for $\mu_{s}{ }^{\prime}$, especially above $40 \mathrm{~cm}^{-1}$, are less accurate, with an $\mathrm{R}^{2}$ of 0.957 and an RMSE of $3.212 \mathrm{~cm}^{-1}$. This could have possibly been caused by the design of the set of calibration phantoms, as values close to the edges of this design showed larger prediction errors.

a)

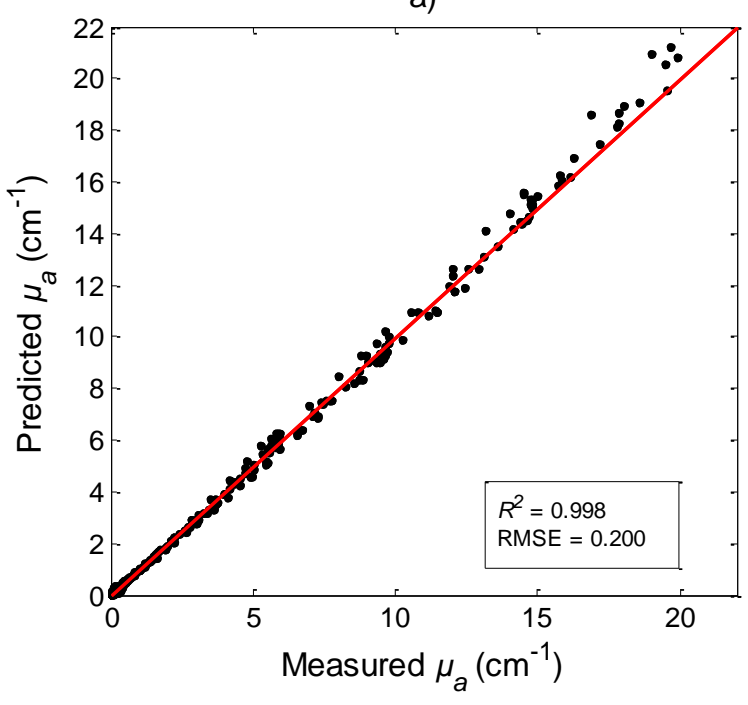

b)

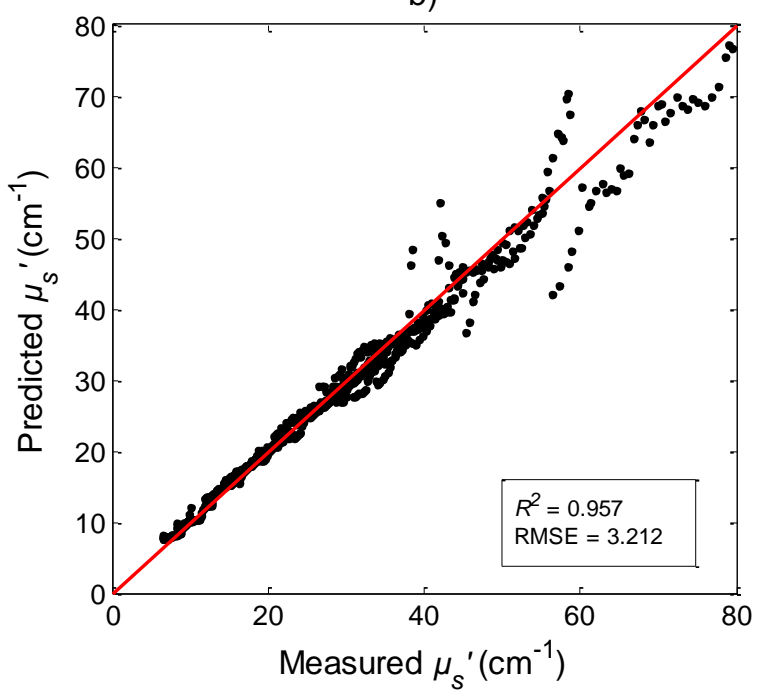

Figure 3. Scatter plots of predicted versus measured (a) bulk absorption coefficient $\mu_{a}$ and

$307 \quad$ 1:1 line. 
310 for a multiscale model predicting the BOP of polydisperse systems. By using the Mie solution

311 for Maxwell's equations, the optical properties of a spherical particle in an absorbing host were

312 simulated. Polydispersity of the particle systems was then supported by discretization of the

313 provided particle size distributions. The number of intervals was optimized automatically in an

314 iterative procedure. As a result, the BOP of the polydisperse system could be obtained in a

315 flexible way. Two aqueous nanoparticle systems and an oil-in-water emulsion (Intralipid ${ }^{\circledR} 20 \%$ )

316 were used for validating the developed tool. The simulated BOP values were compared to the

317 reference BOP measured using a DIS and unscattered transmittance setup (described in Section

318 3.1). This study showed that this type of simulation based on the particle size distribution of the

319 scattering particles matched closely $\left(\mathrm{R}^{2} \geq 0.899\right)$ with the BOP values obtained by the reference

320 measurements. Postelmans et al. (2018) implemented this microscale light propagation tool in an

321 inverse estimation algorithm to develop a shape dependent method for the estimation of particle

322 size distributions from bulk scattering coefficient spectra. They successfully validated this

323 method on simulated data for polystyrene in water suspensions and investigated its sensitivity to

324 measurement errors. They found that a correct estimate for the refractive index mismatch

325 between the particle and the medium is most critical.

327 3. Measurement Techniques

328 In this section, we first describe the integrating sphere technique (i.e., IS-IAD), which is

329 often used as a reference method for evaluating other new techniques, and then the three

330 nondestructive measurement techniques (i.e., SR, TR, and SFD), based on the light illumination

331 conditions presented in Figure 1. All the techniques have been used for measuring optical

332 properties of fruits and vegetables. 


\subsubsection{Instrumentation}

Integrating spheres have been commonly used as an optical calibration and measurement tool and in particular they have been successfully used to measure optical properties of tissues (Jacquez and Kuppenheim, 1955; Tuchin, 2007). The inner surface of an integrating sphere is uniformly coated with highly reflective diffuse materials (e.g., reflectivity $\rho=0.98)$ to achieve homogenous distributions of light radiation at the sphere's inner wall. A light beam falling on the inner surface of an integrating sphere is evenly scattered to all directions (i.e., Lambertian reflections) and the light fluxes are evenly distributed (spatially integrated) on the homogenous inner surface of the sphere after multiple Lambertian reflections. A standard integrating sphere usually has three ports: input port, exit port, and a third port for detector. Plugs with highly reflective materials are also needed to cover the port that should be closed. For real integrating spheres, the surfaces do not have perfect Lambertian reflection. To prevent measurement errors by specular reflection, baffle(s) coated with a highly reflective material is often placed inside the sphere to further diffuse the specular reflection and avoid the direct reflection from reaching the detector. In certain applications, the fourth port is also used so that the specular reflection beam can go out from the sphere in a light trap.

There are several advantages of using integrating sphere techniques to measure the spectral reflectance and transmittance of fruit and vegetable tissue samples, in comparison to directly measuring the sample by a spectrometer. First, in a regular spectrometer measurement where the incident light directly impinges on the sample surface, the detected reflectance often has a dependency on the angle and distance between the incident beam and the detector. When an 
355 integrating sphere is used, the fluxes reflected on the sample are all captured and normalized by

356 the sphere. Thus, the angular dependency is no longer an issue. Second, the detector-object

357 distance is often fixed in the integrating sphere measurement. Even if there is a small change

358 between the sample-sphere distance, it will not affect the results of the measurements as long as

359 all reflected light bounces back into the sphere. Additionally, by using integrating spheres, the

360 spectral measurements are less dependent on the shape of the light beam and the homogeneity of

361 the sample, since both incident light beam and the reflected/scattered light will be normalized on

362 the inner surface of the sphere before being captured by the detector.

Figure 4a shows an example of the instrumentation setup of an integrating sphere system for

364 collecting the spectra of vegetable tissues (Wang and $\mathrm{Li}, 2014$ ). The system consisted of an

365 integrating sphere, a spectrometer, a light source, optical fibers, a collimator, and a slab of tissue

366 sample sandwiched between glass slides. The integrating sphere (model 4P-GPS-060-SF,

367 Labsphere, Inc., North Sutton, NH, USA) had an internal diameter of $152 \mathrm{~mm}$ and four $25.4 \mathrm{~mm}$

368 diameter ports at $0^{\circ}, 90^{\circ}, 180^{\circ}$, and the north pole. The sphere was coated with a highly reflective

369 material (Spectraflect ${ }^{\circledR}$, Labsphere, Inc., North Sutton, NH, USA), whose reflectivity was greater

370 than $98 \%$ in the test spectral range. A Vis/NIR spectrometer (model USB4000, Ocean Optics,

371 Dunedin, FL, USA) and a NIR spectrometer (model CD024252, Control Development, Inc.,

372 South Bend, IN, USA) were used to measure light signals for the two spectral ranges of 550 -

$373880 \mathrm{~nm}$ and $950-1650 \mathrm{~nm}$, respectively. An optical fiber (400 $\mu \mathrm{m}$ diameter and 0.37 numerical

374 aperture) (model M32L02, Thorlabs, Newton, NJ, USA) was used to deliver the light to the

375 spectrometer from the integrating sphere. The light source was provided by a DC-regulated fiber

376 optic illuminator (model DC-950, Dolan-Jenner Industries, Boxborough, MA, USA) with a

377 goose neck light guide. The collimator mounted in front of the light guide was used to collimate 
378 the divergent light of the fiber optic illuminator to a $1.5 \mathrm{~mm}$ diameter light beam. Each vegetable

379 tissue sample was sandwiched between two pieces of Borofloat glass slide (transmittance >

$38090 \%$ ), covering the whole entrance or exit port of the integrating sphere.

381 The total transmittance $T$ was measured when the sample was placed in front of the entrance

382 port of the sphere and the opposite exit port was covered by a Spectraflect plug (Figure 4b). The

383 total reflectance $R$ was measured when the sample was placed behind the exit port (Figure $4 \mathrm{c}$ ).

384 To measure collimated transmittance $T_{c}$, a 1-mm diameter iris was placed between the collimator

385 and the sample to constrain the position and the size of the incident beam, and the other iris in

386 front of the detector blocked the ambient scattered light from entering the spectrometer (Figure

387 4d) (Prahl, 2011).

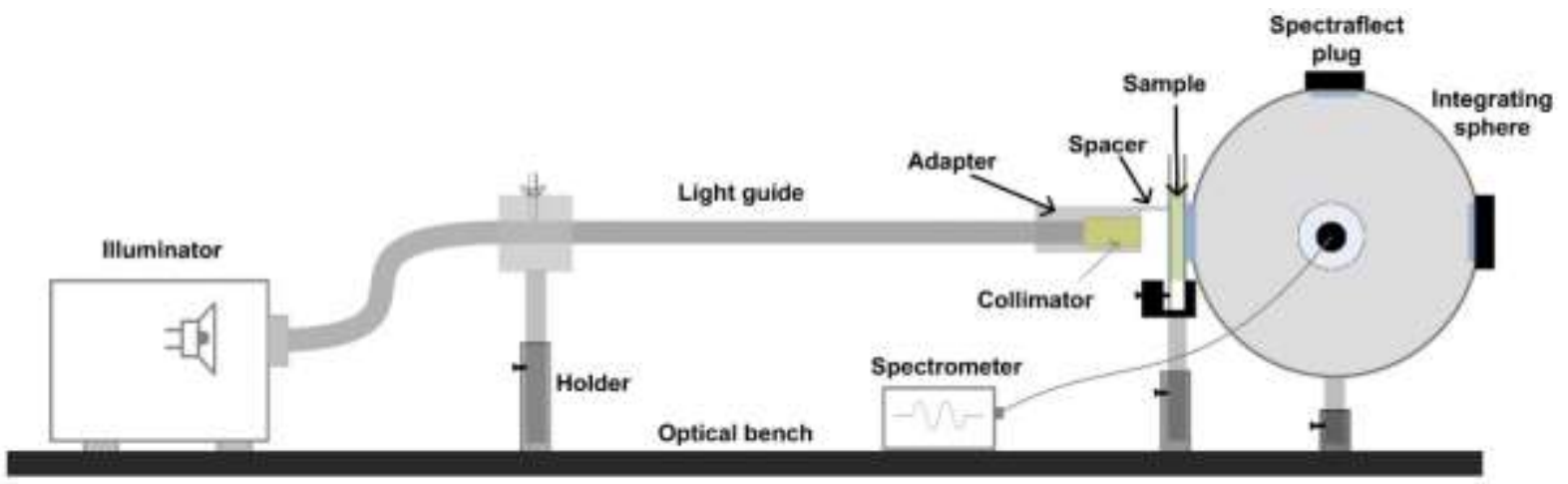

(a)



(b)

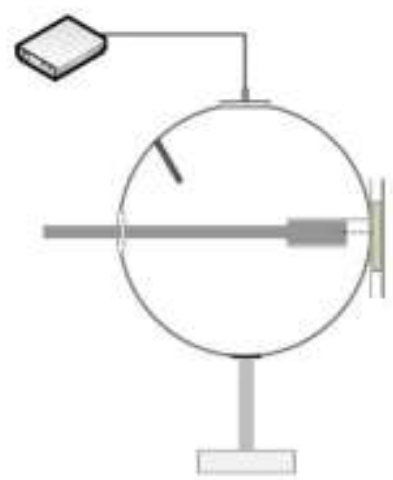

(c)

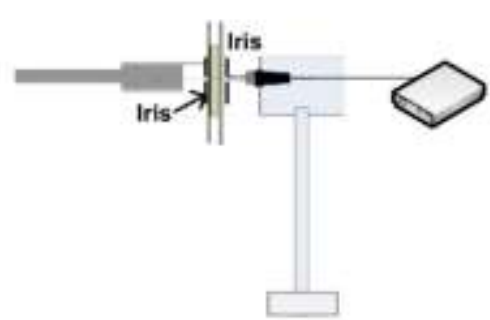

(d) 
Figure 4. The hardware components of the integrating sphere-based spectroscopic system (a), and the schematics for measuring the three types of spectra: the total transmittance $T(\mathrm{~b})$, the

391 total reflectance $R(\mathrm{c})$, and the collimated transmittance Tc (d) (Wang and Li, 2014).

\subsubsection{Data analysis}

The optical responses $\left(\mathrm{R}, \mathrm{T}\right.$, and $\left.\mathrm{T}_{\mathrm{c}}\right)$ measured using the spectrometer and the integrating

394 sphere are processed by the inverse adding-doubling (IAD) algorithm to obtain the optical

395 properties of fruit and vegetable tissue samples. IAD (Pickering et al. 1993; Prahl et al., 1993) is

396 one of the most common and accurate methods to calculate the light scattering and absorption

397 coefficients of samples based on their reflectance and transmittance (Tuchin, 2007). It is the

398 inverse algorithm of the adding-doubling method, which has been described in Section 2.3. The

399 general procedure of the IAD algorithm is illustrated in Figure 5.

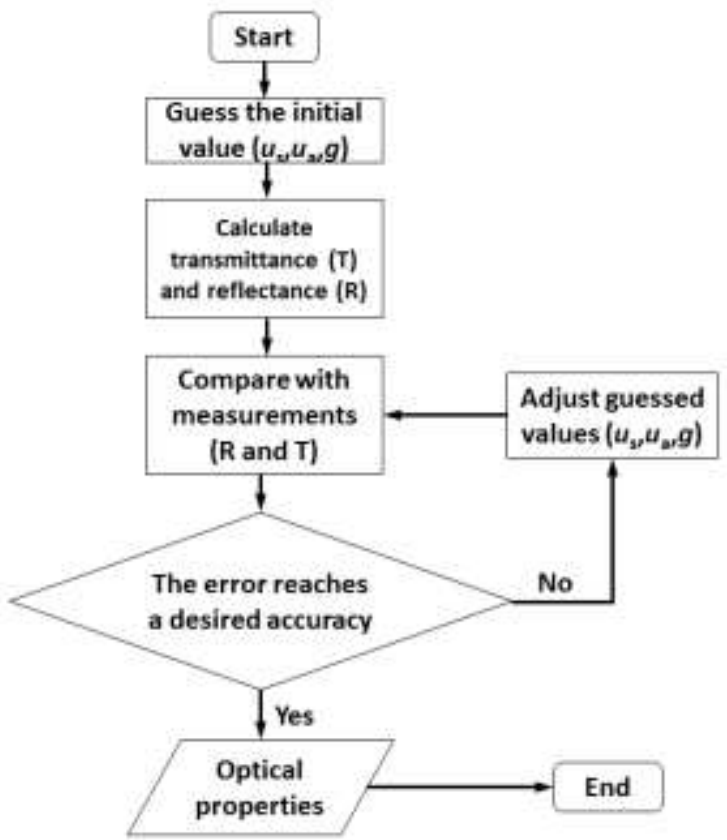

401 Figure 5. Flowchart of the inverse adding-doubling (IAD) algorithm. 
In implementing the IAD method, it is essential to measure the reflectance and transmittance

404 of the sample by integrating spheres. In addition to the method introduced in the previous section

405 using a single integrating sphere to measure reflectance and transmittance, double integrating

406 sphere setups can also be used to obtain both reflectance and transmittance measurements

407 simultaneously (Pickering et al., 1993, Aernouts et al., 2013). The double integrating sphere

408 setup with single beam is simple to construct and use, but it requires two integrating spheres.

409 In the past decade, the IS-IAD method has been used to measure the optical properties of

410 food items. For instance, Saeys et al. (2008) and Van Beers et al. (2017b) measured the $\mu_{a}, \mu_{s}$

411 and $g$ of the apple skin and flesh in 350-2200 $\mathrm{nm}$ using a double integrating sphere configuration

412 in combination with the IAD method for different apple cultivars and at different maturation

413 stages. Lopez-Maestresalas et al. (2015) measured the optical properties of potato flesh in the

414 500-1900 $\mathrm{nm}$ range. Wang and Li (2013) measured the optical properties of the skin and flesh of

415 four common types of onions at $633 \mathrm{~nm}$ and reported that the optical properties of onion tissues

416 were significantly different between onion cultivars. The group also used the IS-IAD method to

417 investigate the optical properties of healthy and diseased onion tissues in a broad spectrum (550-

$418880 \mathrm{~nm}$ and 950-1650 nm) (Wang et al., 2014). Fang et al. (2016) used a similar method to

419 measure absorption and scattering coefficients of kiwifruit tissues at the wavelength of $633 \mathrm{~nm}$.

420 The IS-IAD method also provides good reference measurements for the development of other

421 techniques (e.g., SR, TR and MC) for measuring optical properties of food items (Cen et al.,

422 2013; Lu, 2008; Qin and Lu, 2009). 
444 configurations used for measuring optical properties of fruit and food products, which consists of 445 five optical fibers arranged at different distances. The rigid FOP only covers the maximum

\subsection{Spatially resolved}

Spatially resolved (SR) technique was first developed by Reynolds et al. (1976) for understanding light propagation in turbid media. Later, Langerholc (1982) and Marquet et al. (1995) reported that SR measurements can be used to determine optical properties of biological tissues. In this method, a small continuous-wave light beam perpendicularly illuminates the sample's surface, and the reemitted light is measured at different distances from the light source (Figure 1a). The absorption coefficient $\left(\mu_{a}\right)$ and the reduced scattering coefficient $\left(\mu_{s}{ }^{\prime}\right)$ can then be extracted from the measured SR reflectance profiles by using a numerical method or an appropriate analytical solution to the diffusion equation, coupled with an inverse algorithm.

\subsubsection{Instrumentation}

SR technique is well suited for use in postharvest applications thanks to its low instrumentation cost, easy implementation and nondestructive measurement setup. Hence, many different SR measurement configurations have been developed for horticultural and food products. Optical fiber arrays and non-contact reflectance imagery are two typical sensing configurations in SR measurement (Doornbos et al., 1999; Fabbri et al., 2003; Malsan et al., 2014; Pilz et al., 2008), which can be implemented with fiber optic probe (FOP), monochromatic imaging (MCI), and hyperspectral imaging (HSI). Figure 6 shows four instrumental setups with SR technique for measuring optical properties of fruits and vegetables. In the FOP measurement, a single spectrometer, multiple spectrometers, or a spectrograph-camera combination coupled with multiple detection fibers can be used to measure diffuse reflectance at different distances from the light incident point (Nguyen Do Trong et al., 2014a). Figure 6a shows one of the FOP 
446 spatial distance of $1.5 \mathrm{~mm}$ and hence it can only measure tissues of homogeneous properties or

447 the superficial layer of the sample. Since most fruit and vegetable products are of curved or

448 irregular shape, a rigid FOP would have problem maintaining good contact with the sample

449 during measurement. Moreover, it is also desired or needed to measure the sample tissue at

450 greater depth. To overcome the shortcomings of a rigid FOP, a flexible FOP with 30 optical

451 fibers covering a spatial distance range of 0-30 $\mathrm{mm}$ was developed for measuring the optical

452 properties of fruits and vegetables (Huang et al., 2017). The optical fibers are coupled to a

453 multichannel hyperspectral imaging system, which allows simultaneous acquisition of $30 \mathrm{SR}$

454 spectra from the sample. The use of three different sizes of fibers $(50,120$ and $200 \mu \mathrm{m})$ for the

455 probe also effectively expands the dynamic range of the camera, allowing to acquire spectra

456 from the sample at greater distances.

457 As a non-contact method, MCI is more suitable for measuring optical properties of fruits and 458 vegetables at one single wavelength. A laser diode or a combination of a supercontinuum laser 459 and monochromator can be used to illuminate the sample at a specific wavelength (Baranyai and 460 Zude, 2009; Van Beers et al., 2015). SR diffuse reflectance is then acquired with a CCD camera 461 (Figure 6c). This SR configuration is simple and relatively easy to implement. The acquired 2-D 462 scattering images are reduced to 1-D scattering profiles by radial averaging (assuming the 463 scattering images are axisymmetric with respect to the laser incident point). However, this 464 assumption does not hold for anisotropic tissues where the light is guided by the tissue fibers. 465 For example, in the case of bovine muscle tissue, the effect of the fibers resulted in scatter spots 466 with a rhombus shape (Van Beers et al., 2017a). Measurement at multiple wavelengths requires 467 sequential wavelength scanning. In addition, a substantial portion of the signal of each pixel 468 comes from the surrounding areas, which can affect measurement accuracy. Characterization of 
469 the point-spread function (PSF) could be helpful to obtain accurate intensity values for the image 470 data interpretation (Du and Voss, 2004; Pilz et al., 2008).

471 In hyperspectral imaging, spectral and spatial information is acquired simultaneously. This is

472 therefore advantageous for measuring SR diffuse reflectance profiles over a broad spectral range

473 (e.g., 400-1000 nm). Figure 6d shows a hyperspectral imaging-based SR system in line scan

474 mode, which mainly consists of a high-performance CCD camera, an imaging spectrograph, a

475 zoom or prime lens, a light source, and an optical fiber coupled with a focusing lens for

476 delivering a small broadband beam to the sample (Cen et al., 2012b). This SR configuration

477 allows fast acquisition of SR spectra from the sample at high spatial resolution, and it typically

478 covers a spatial distance range of about $10 \mathrm{~mm}$ for plant products like apples and peaches. In the

479 HSI configuration, two key factors, i.e., light beam and source-detector distance, need be 480 carefully considered in order to meet the requirements of the diffusion approximation theory

481 (Cen and Lu, 2010).

482

483
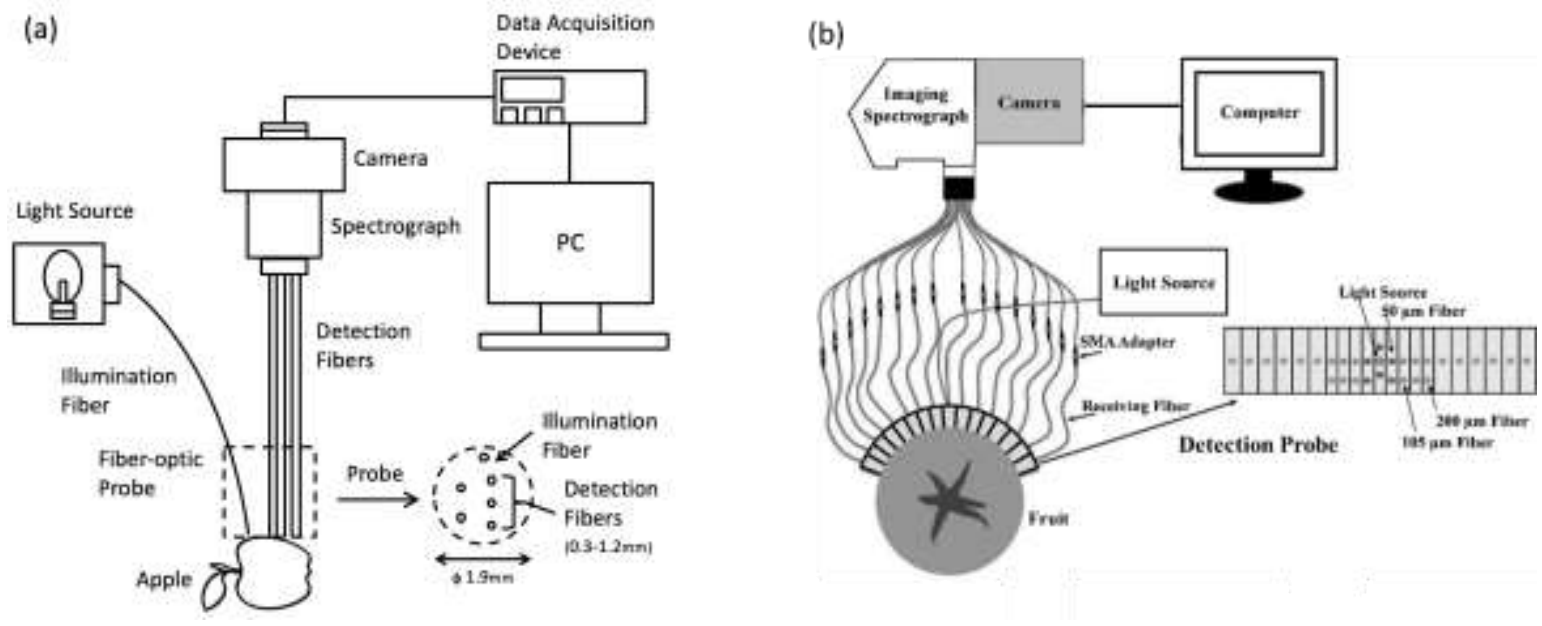
(c)

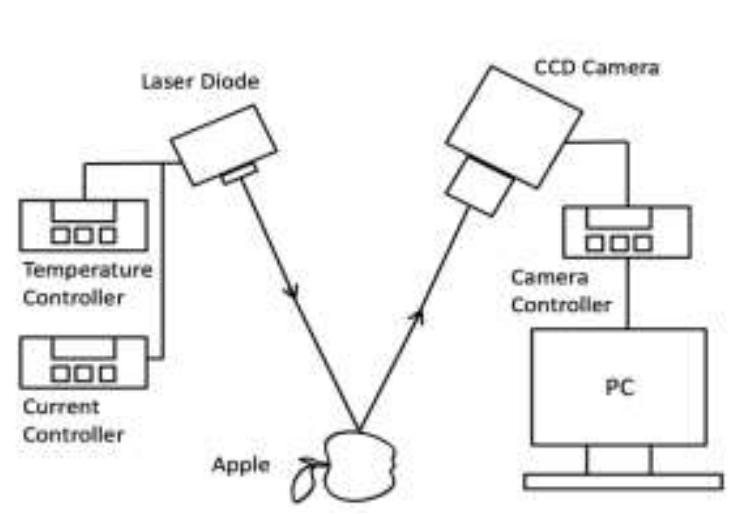

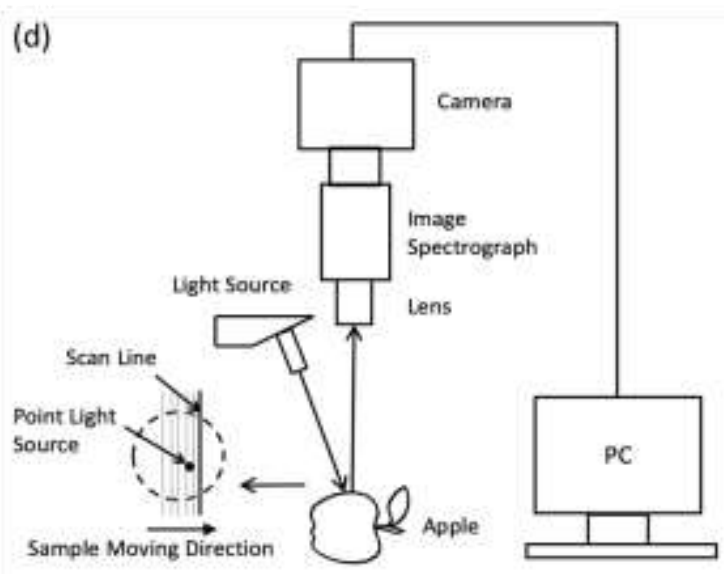

484

485

486

487

488

489

490

491

492

493

494

495

496

497 evaluating their quality attributes (Cen et al., 2012a, 2012b; Qin et al., 2009; Van Beers et al.,

498 2015; Zhu et al., 2015).

499

500

Figure 6. Schematic illustrations of (a) a fiber-optic probe with a rigid plate (Nguyen Do Trong et al., 2014a), (b) a fiber-optic probe with a flexible plate mounted with 30 optical fibers (Huang et al., 2017), (c) monochromatic imaging (Baranyai and Zude, 2009), and (d) hyperspectral imaging-based spatially resolved systems (Cen et al., 2012b).

measuring fruit and vegetables. FOP has been used for estimating optical properties of dried apples (Nguyen Do Trong et al., 2014b), fresh apples (Nguyen Do Trong et al., 2014a), and tomatoes (Huang et al., 2018). MCI technique was used for optical characterization of apples, kiwifruit, pears and oranges (Adebayo et al., 2017; Baranyai and Zude, 2009; Lorente et al., 2013; Mollazade and Arefi, 2017), while the HSI-based SR technique has been used for measuring apples, peaches, pickling cucumbers, tomatoes, and sugar beets as well as for 2015; Zhu et al., 2015). 
As an indirect method for optical property measurement, computation of the optical

502 parameters from the SR measurements usually requires sophisticated modeling based on the

503 radiative transfer theory, diffusion approximation, or MC simulation, coupled with appropriate

504 inverse algorithms. Numerical methods are generally required for solving the radiative transfer

505 equation or using inverse MC simulation. These methods need no or fewer physical

506 approximations on photon transport in the media, but they could be subjected to statistical

507 uncertainties during the estimation of the reflectance. One major drawback with the numerical

508 methods is that they require substantial computational time. Therefore, it has been proposed to

509 build a library of MC simulated SR profiles for a grid of $\mu_{s}, \mu_{a}$ and $g$ values. This library can

510 then be used either as a look-up table (Hjalmarsson and Thennadil, 2007; Sharma et al., 2014) or

511 for training a neural network (Hjalmarsson and Thennadil, 2008). As discussed earlier, databased

512 models, such as metamodels, can also be used to model the relation between diffuse reflectance

513 and BOP (Watté et al., 2015). This has been demonstrated both for FOP-based SR (Watté et al.,

5142015 ) and HSI-based SR (Aernouts et al., 2015) systems. A popular and faster approach is to use

515 the analytical equation derived by Farrell et al. (1992) or Kienle and Patterson (1997), coupled

516 with an appropriate inverse algorithm, to obtain the estimates of $\mu_{a}$ and $\mu_{s}{ }^{\prime}$ from the acquired SR

517 diffuse reflectance profiles (Cen et al., 2012a, 2012b; Erkinbaev et al., 2014).

518 Accurate estimation of the optical parameters by inverse algorithms is not an easy task due to 519 the complexity of the analytical solutions and potential experimental errors in measuring diffuse

520 reflectance from the medium. In general, optical parameter estimation can be defined as a

521 nonlinear least squares optimization problem with several important assumptions (i.e., constant

522 variance errors, uncorrelated errors, and the Gaussian distribution of errors). The results will not

523 be valid if these assumptions are violated. Cen et al. (2010) recommended using data 
524 transformation and weighting methods as a pre-processing approach before implementing the

525 inverse algorithm. Since the optical parameters are sensitive to the SR reflectance profile, high

526 noise level and improper selection of the profile region could result in large estimation errors. In

527 addition, for estimating the optical parameters of layered media, the increased number of free

528 parameters can dramatically increase the computational time, further exacerbating the estimation

529 of optical parameters, and/or causing ill-posed problems. Different strategies, such as a multi-

530 step method, sensitivity analysis and statistical evaluation, have been proposed to optimize the

531 inverse algorithms and improve the estimation accuracies (Cen et al., 2010; Hu et al., 2019;

532 Wang et al., 2017a; 2017b).

533 In contrast to the above inverse approach for estimating the optical absorption and scattering

534 coefficients of fruits and vegetables, researchers have also proposed several direct approaches to

535 characterize the obtained SR profiles for quality assessment of fruit and vegetables. With these

536 direct methods, the acquired SR profiles (usually after corrections for the dark and instrument

537 responses) are fitted with some empirical mathematical equations (e.g., Gaussian and Lorentzian

538 functions, etc.) (Peng and Lu, 2006, 2007) or by extracting image features (including mean

539 reflectance, image histogram, scattering size or area, etc.) from the 2-D scattering images (in the

540 cases of monochromatic or multispectral scattering images) (Qing et al., 2008; Lu, 2004;

541 Romano et al., 2011; Tu et al., 2000). While these direct methods are faster and simpler in

542 extracting the features from the SR profiles and also have yielded good results in predicting

543 quality of fruits and vegetables, they are highly dependent on type of instrumentation and light

544 source/detector setup.

545 


\subsection{Time-resolved}

In TR technique, ultrashort laser pulses are injected into a turbid sample, and temporal responses of the reemitted light at a certain distance away from the laser incident point are recorded (Figure 1b). The temporal responses are a function of time. After acquisition of the time-resolved reemitted light intensity signals, the absorption and reduced scattering coefficients are then estimated by fitting the acquired TR data using an inverse algorithm for an analytical solution for the diffusion equation.

\subsubsection{Instrumentation}

Figure 7 shows the schematic of a TR system for measuring optical properties of turbid biological samples. The two key components for the TR system are a laser (or lasers for a multiple wavelength system, or a tunable laser for a broad spectral region), which can generate ultrashort pulses at the repetition frequency up to $100 \mathrm{MHz}$, and a time-correlated single photon counting (TCSPC) device, which counts the number of photons arriving at the detector for different time intervals. Hence, the detection system essentially records the histogram of the detection times for the reemitted photons from the sample. To accurately measure the optical properties of tissues, the TCSPC device needs to have the capability of providing sufficient time resolution down to picoseconds $\left(10^{-12} \mathrm{~s}\right)$ or even femtoseconds $\left(10^{-15} \mathrm{~s}\right)$. A high temporal resolution and high sensitivity are critical to the performance of a TR system. Temporal resolution is related to both the width of laser pulses and the timing accuracy of the detection electronics. To achieve high sensitivity, it is desirable to have a high-power laser (or lasers), but a laser with excessive power can cause damage to biological tissues and pose safety concerns. Hence, there is a delicate balance between sensitivity and safety in choosing an appropriate level of laser power for a TR system. Over the years, many different TR techniques have been 
569 developed for biomedical applications (Tuchin, 2007, Wang and Wu, 2007). Three TR

570 instrumentation configurations were developed by a group of researchers in Italy for measuring

571 the optical properties of biological tissues and horticultural products over a broad spectral range,

572 at a single wavelength, and at select discrete wavelengths (Rizzolo and Vanoli, 2016). TR

573 imaging systems have also been reported for 3-D imaging of biological tissues (Hebden et al.,

574 2004; Pifferi et al., 2003).

575 Compared to SR and SFD methods, the TR method is considered to be more accurate in

576 measuring optical properties and able to interrogate deeper tissues, which is important in

577 assessing quality and internal defects of horticultural products with a relatively thick surface

578 layer (i.e., skin or rind). However, TR techniques are expensive and complex, even for a portable

579 TR instrument. Moreover, it is important to have good contact of the detection probe with the

580 sample during the measurement, which may not be easy in working with intact fruit and

581 vegetable products of curved or irregular shape.

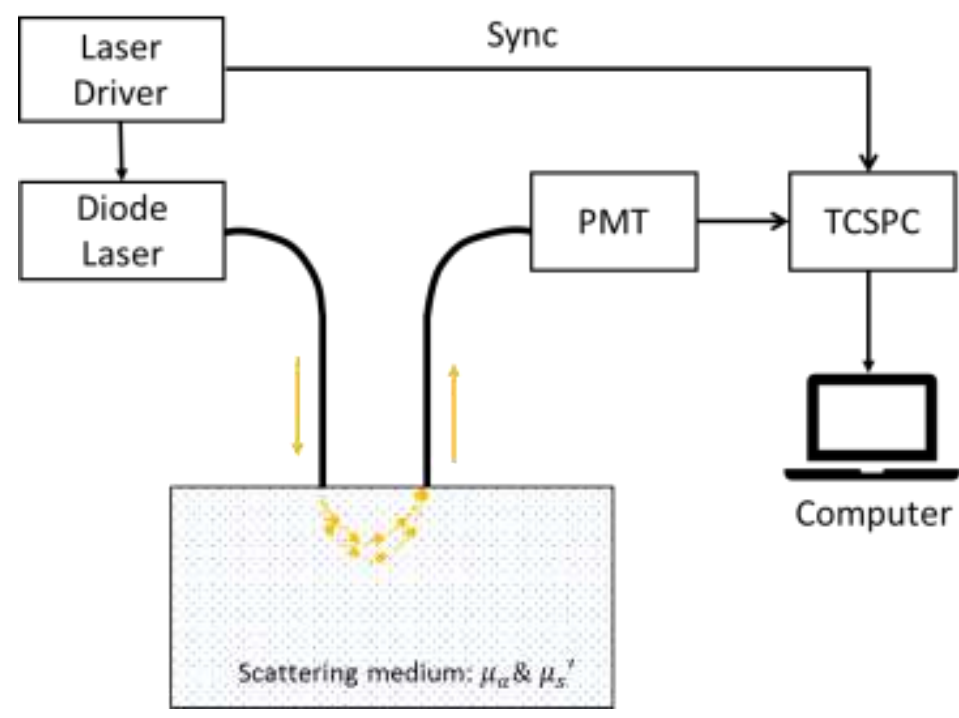

583 Figure 7. Schematic of a single-wavelength time-resolved system for measuring optical 584 properties of biological tissues, where PMT is a photomultiplier tube for detecting single photons 
585 and TCSPC represents a time-correlated single photon counting device synchronized with the

586 laser driver.

\section{$587 \quad 3.3 .2 \quad$ Data analysis}

In principle, once the temporal response curves have been obtained for samples, values of $\mu_{a}$ 589 and $\mu_{s}{ }^{\prime}$ can be obtained by fitting the data using a nonlinear inverse algorithm for an analytical 590 solution for the diffusion approximation equation (Patterson et al., 1989). However, like the case 591 discussed earlier for SR technique, due to the complex instrument response to optical signals, a 592 direct curve-fitting approach could result in large errors in the estimation of optical 593 parameters.Torricelli (2009) proposed to convolute the theoretical TR reflectance with the 594 instrument response function is first calculated, which is then used to fit the experimental TR 595 reflectance curve. According to Torricelli (2009), this approach yielded better results compared 596 to the approach of directly using the acquired TR data.

\subsection{Spatial-frequency domain}

599 Spatial-frequency domain (SFD) technique was first reported by Cuccia et al. (2005) as a 600 means for estimating the optical absorption and scattering properties of turbid media. The 601 technique is different from SR and TR in that it allows wide-field mapping of optical properties 602 in turbid biological materials. Thus, it has the capability of 3-D imaging of biological tissues. 603 Instead of using a point light source for SR and TR techniques, SFD requires using special 604 patterns of 2-D illumination (usually sinusoidal patterns). To estimate the optical properties, 605 reflectance images are acquired from the sample with different spatial frequencies of 606 illumination, and the acquired images are then demodulated to obtain direct component (DC) and 607 alternating component (AC) images. The amplitudes of reflectance from the demodulated images 
608 are then used for the inverse curve fitting by an analytical diffusion equation (Cuccia et al., 2009)

609 to obtain the estimated values of $\mu_{a}$ and $\mu_{s}{ }^{\prime}$.

\subsubsection{Instrumentation}

Figure 8 shows the schematic of an SFD system for measuring optical properties of fruits and

612 food products. The system mainly consists of a high-performance CCD camera, a liquid crystal

613 tunable filter (LCTF), which allows selecting specific wavelengths for imaging, a polarizer that

614 blocks specular reflectance from the sample, and a digital light projector (DLP), which is

615 controlled by computer and connected to a DC light source via a fiber optic cable. The DLP can

616 generate different patterns of illumination through computer programming. For optical property

617 measurements, sinusoidal patterns of illumination are used to illuminate samples. For each

618 spatial frequency, three patterned images, corresponding to three phase-shifted sinusoidal

619 illumination patterns (120 degrees apart), are usually needed. To estimate the absorption and

620 reduced scattering coefficients, images should be acquired for a range of spatial frequencies. To

621 ensure accurate measurement of optical properties of turbid food samples, several calibration

622 procedures have to be carried out for an SFD system (Bodenschatz et al., 2014). First, it is

623 important that the camera system has good linearity responses. Second, under the ideal situation,

624 the illumination patterns should be sinusoidal. However, this may not always be realized due to

625 optical system imperfections and a specific setup of the light source. Hence, careful calibrations

626 should be done on standard reflectance panels (e.g., the reflectance panels by Labsphere, Inc.,

627 North Sutton, NH, USA). For the SFD setup configuration shown in Figure 8, the light

628 illumination is not incident onto the sample from the vertical or normal direction, which would

629 create nonuniform illumination on the sample and should thus be corrected. In addition, the light

630 illumination along the second axis should be constant in intensity, but in real situations, this may 
631 not always be the case. Hence, careful calibration of the system is required to eliminate or

632 minimize these effects.

633

634

635

636

637

638

639

640

641

642

643

644

645

646 647 which the absorption and reduced scattering coefficients are estimated for each wavelength. In

Figure 8. Schematic of a spatial-frequency domain imaging system for measuring optical properties of horticultural products (Lu et al., 2016a).

\subsubsection{Data analysis}

Figure 9 shows a typical procedure for implementing the SFD technique for estimating optical absorption and reduced scattering coefficients. First, two or three phase-shifted images are acquired for each spatial frequency at each wavelength. The number of spatial frequencies used varied in different studies; some used more than 12, while others only used a few (e.g., 4 to 6). The next step is to perform demodulation of the acquired pattern images, from which DC and AC images are obtained. The conventional demodulation method requires three images, while using new methods, such as spiral phase transform and Gram-Schmidt orthonormalization, two patterned images would be enough (Lu et al., 2016b, 2016c). After the demodulation, the reflectance values (the amplitude) are extracted. The extracted reflectance profile versus spatial frequency is then fitted by the diffusion model with an appropriate inverse algorithm, from 
648 performing the inverse algorithm for curve fitting, one should be aware that the analytical 649 solution for the SFD method is derived based on two basic assumptions: 1) scattering is 650 dominant (i.e., $\mu_{s} \gg \mu_{a}$ ), and 2) the spatial frequency is much smaller than the transport 651 coefficient (i.e., $\mu_{t r}=\mu_{a}+\mu_{s}^{\prime}$ ). Studies have shown that SFD technique is prone to errors due to 652 the complexity of the diffusion model and low signal-to-noise ratio for measured data at large 653 spatial frequencies. It is therefore important that proper inverse algorithm implementation 654 procedures are utilized, which include data smoothing, selection of proper spatial frequency 655 range and start and end frequencies. An SFD system consists of many optical components (lens, 656 tunable filter, detector, etc.), each of which has different optical response characteristics. The 657 optical response of the optical assembly will have important ramifications on the acquired 658 reflectance images. Hence, proper calibrations of the optical system are needed to reduce or 659 minimize errors in estimating the optical properties. Hu et al. (2019) suggested that the most 660 effective method for image correction is to use reference samples covering a range of known 661 properties to calibrate the acquired or demodulated reflectance images. Two-step and stepwise 662 optimization methods, including the reference-sample based correction procedure, were 663 proposed to improve the optical parameter estimation by SFD technique (Hu et al., 2018, 2019). 




665 Figure 9. The procedure of implementing spatial-frequency domain technique for measuring 666 optical properties of fruit and vegetable samples (* AC and DC denote amplitude and direct 667 components, respectively).

668 So far, only limited studies have been reported on using SFD technique for optical 669 characterization of fruits and vegetables, including apples, mangoes, and pears (Anderson et al., 670 2007; He al et., 2017, 2018; Hu et al., 2016).

671 Similar to SR technique, a direct approach for SFD technique, called structured-illumination 672 reflectance imaging (SIRI), has been proposed as a new imaging modality for quality evaluation 673 of horticultural products (Lu, 2018; Lu and Lu, 2017b; Lu et al., 2016a). The SIRI system shares 674 the same optical configuration as that for the SFD system as shown in Figure 8, and the same 675 demodulation procedure is used to obtain DC and AC images. Instead of using the inverse 676 algorithm to estimate the optical absorption and reduced scattering coefficients, SIRI directly 677 applies image processing procedures on the DC and AC images to extract image features for 
678 evaluating quality of fruits and vegetables. Studies (Li, et al., 2018; Lu et al., 2017b) showed that 679 AC images, which are unique to the SIRI technique, provide higher spatial resolution and image 680 contrast and can reveal subsurface tissue features at specific depths, compared to DC images, 681 which are equivalent to the ones acquired under uniform, diffuse illumination. SIRI was found to 682 be especially useful for detecting subsurface defects (e.g., bruising in apples and tomatoes) and 683 early developments of fungal infection in peaches and other fruits (Sun et al., 2019), which are 684 difficult to ascertain by other conventional imaging techniques.

\section{Applications}

Considerable research has been reported in recent years on using IS-IAD, SR, TR and SFD techniques to measure optical absorption and scattering properties of fruits and vegetables as well as on using these optical properties for maturity and quality assessment and for disease and

690 defect detection. As discussed in Section 3, direct approaches for analyzing SR and SFD signals 691 also have been proposed for evaluating quality of horticultural and food products. However, our

692 discussion in this section is mainly focused on the application of optical absorption and 693 scattering properties for quality assessment of fruits and vegetables.

$694 \quad 4.1 \quad$ Absorption and scattering spectra for fruits and vegetables

Figure 10 shows typical mean absorption coefficient $\left(\mu_{a}\right)$ spectra for the apple skin (Figure 696 10a) and cortex tissues (Figure 10b) of three apple cultivars ('Braeburn', 'Greenstar', and 697 'Kanzi') in the spectral region of 500-1850 nm, which were measured using an IS-IAD technique 698 (Van Beers et al., 2017b). The insert in Figure 10b shows a close-up of the absorption coefficient 699 for the apple cortex in the 500-1000 $\mathrm{nm}$ region. Several absorption peaks are observed for the 
700

701

702

703

704

705

706

707

708

709

710

711

712

713

714

715

716

717

718

apple skin over the visible region of 550-680 nm, which are attributed to carotenoids (around 500 $\mathrm{nm}$ ), anthocyanins $(550 \mathrm{~nm}-600 \mathrm{~nm})$ and chlorophyll (mainly chlorophyll a at $678 \mathrm{~nm}$ ). Absorption peaks around $678 \mathrm{~nm}$ are also noticed for the apple cortex; however, their values are at least 10 times smaller than those for the apple skin, which indicates the presence of chlorophyll and carotenoids, albeit at much lower concentration levels, in the apple cortex. In addition, the $\mathrm{OH}$ bonds in water also have an important effect on the absorption coefficient for both apple skin and cortex in the NIR region around $970 \mathrm{~nm}, 1200 \mathrm{~nm}$ and $1450 \mathrm{~nm}$ (Hale and Querry, 1973; Lancaster et al., 1994; Merzlyak et al., 2003). Differences between the cultivars can also be observed. For example, absorption at $550 \mathrm{~nm}$ is much lower for 'Greenstar', a green cultivar with little anthocyanins in the skin.

Absorption spectra reported for other fruit and vegetables (apple, blueberry, kiwifruit, mango, onion, peach, pear, pickling cucumber, plum, tomato, zucchini squash) are also largely dominated by water in the NIR range and chromophores like chlorophyll, carotenoids and anthocyanins in the visible range (Cen et al, 2012; Cen et al., 2013; Cubbedu et al., 2001; Huang et al., 2018b; Lu et al., 2011; Nguyen Do Trong et al., 2014; Nicolai et al., 2008; Qin and Lu, 2008; Saeys et al., 2008; Spinelli et al., 2012; Vanoli et al., 2011; Wang et al., 2014; Zhang et al., 2017a). For example, in immature tomatoes (i.e., in the green and breaker stages) chlorophyll dominates the visible spectral region, while for ripe, red tomatoes, chlorophyll disappears, and carotenoids (mainly lycopene) increase significantly (Clément et al., 2008; Huang et al., 2018). 

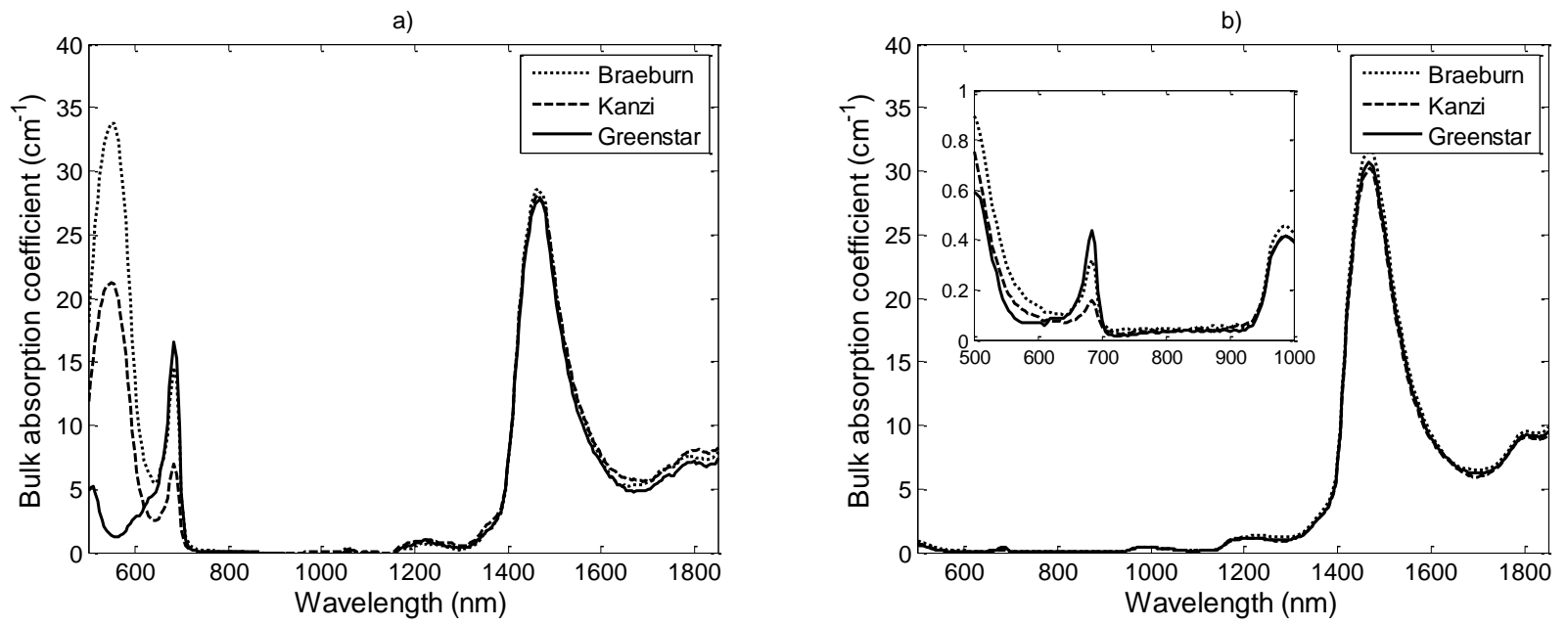

Figure 10. Mean absorption coefficients of the apple skin (a) and cortex (b) tissues of three apple

The mean reduced scattering coefficient $\left(\mu_{s}{ }^{\prime}\right)$ spectra for the apple skin and cortex tissues of

723 the same three cultivars are illustrated in Figure 11(Van Beers et al., 2017b). The reduced

724 scattering coefficient decreases exponentially with the increasing wavelength, which is typical

725 for biological tissues (Bashkatov et al., 2005). Again, differences are noticed between the

726 different cultivars and between the tissue types. These differences in the scattering behavior

727 typically relate to differences in the microstructure, like differences in the cell structure and

728 porosity in both tissue types. Other researchers also reported $\mu_{s}^{\prime}$ values for different fruits,

729 ranging between $0 \mathrm{~cm}^{-1}$ and $20 \mathrm{~cm}^{-1}$ (Cen et al., 2012, 2013; Huang et al., 2018; Nguyen Do

730 Trong et al., 2014; Qin and Lu, 2008; Rowe et al., 2014; Saeys et al., 2008; Seifert et al., 2015). 
a)

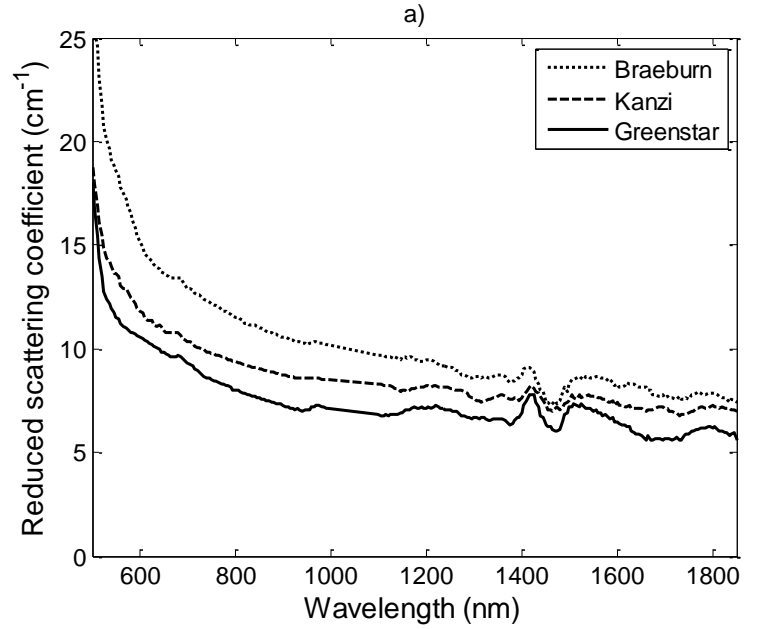

b)



Figure 11. Mean reduced scattering coefficients of the (a) skin and (b) cortex tissue of three apple cultivars (Van Beers et al., 2017b).

In studying the effect of pre-harvest maturation on the optical properties, Van Beers et al. (2017b) found significant changes in the optical behavior of the apple tissues. The absorption by anthocyanins was found to increase, while the scattering coefficients $\left(\mu_{s}\right)$ of the apple cortex decreased. It was hypothesized that this evolution in scattering could be related to cell elongation during maturation, reducing the volume fraction of cell walls and air pores encountered by the light (Van Beers et al., 2017b).

In studying the effect of bruising on the absorption and scattering properties of apples over time, Lu et al. (2010) reported that while no consistent pattern of changes in the absorption spectra over time was observed, there was, however, a steady decreasing trend in the values of $\mu_{s}{ }^{\prime}$ over time. A similar trend of changes in the absorption and reduced scattering coefficients for the spectral region of 950-1400 nm was also reported for healthy and bruised blueberries when IS-IAD was employed (Zhang et al., 2017a). These studies suggested that bruise detection could be enhanced by utilizing the scattering properties of fruit. Wang et al. (2014) measured the 
747 absorption and reduced scattering coefficients for healthy and diseased onion tissues in the

748 spectral region of 550-1650 $\mathrm{nm}$. They reported that values of the reduced scattering coefficient

749 for dry skin were 10 times higher than that of onion flesh. Likewise, large differences in the

750 absorption coefficient values over the spectral region of 550-1300 nm were observed between

751 dry skin and flesh onion tissues.

$752 \quad 4.2 \quad$ Maturity and quality assessment

753 Maturity determines when fruits or vegetables should be harvested and how they should be

754 stored or marketed after harvesting. Maturity directly influences postharvest quality and shelf life

755 of horticultural products. Hence, nondestructive measurement of product maturity before and at

756 harvest is critical for the fruit and vegetable industries. Generally, maturity assessment requires

757 measuring multiple quality attributes. Different fruits and vegetables may have different

758 requirements or standards for assessing maturity. For instance, in assessing the maturity of

759 apples, multiple quality parameters, including fruit surface color, soluble solids content (SSC),

760 starch pattern index, flesh firmness and even titratable acidity, are often used. On the other hand,

761 tomato maturity is mainly judged based on the surface or flesh color distributions, upon which

762 tomatoes are classified into six maturity or ripeness grades. The maturation of fruits or

763 vegetables is accompanied with changes in the chemical composition and structural

764 characteristics. Consequently, the absorption and scattering properties also change during the

765 maturation process, although the trend and magnitude of changes for the two optical properties

766 are different. Hence, optical absorption and reduced scattering coefficients are useful for

767 assessing multiple maturity parameters of fruits and vegetables. Table 1 lists some recent studies

768 on assessing maturity and quality of fruits and vegetables, including apple, banana, kiwifruit,

769 mango, nectarine, peach, pear, plum and tomato, by using IS-IAD, SR, TR and SFD techniques. 
770 Not surprising, most studies were focused on using the two optical parameters measured by SR

771 and TR techniques to predict firmness and SSC, the two most important quality attributes for a

772 variety of fruits. These studies have demonstrated that both absorption and reduced scattering

773 coefficients were related to firmness, SSC, flesh color, and starch index. However, the absorption

774 coefficient overall was better for predicting these quality parameters, which could be attributed

775 to the fact that pigments and other chemical composition change during maturation,

776 accompanied with changes in the cellular structures. In most cases, it was also found that

777 combination of the two optical parameters tended to improve predictions of the fruit

778 maturity/quality parameters (Barzaghi et al., 2009; Cen et al., 2012; Huang et al., 2018a, 2018b;

779 Qin and Lu, 2009; Vanoli et al., 2011). However, Nguyen Do Trong et al. (2014a) reported the

780 best results for SSC prediction based on the absorption coefficient spectra. While few studies

781 have been reported on directly comparing the performance of SR and TR techniques with

782 conventional Vis/NIR spectroscopy, the overall results appeared to be comparable between the

783 two approaches (Barzaghi et al., 2009; Huang et al., 2018a, 2018b). The current optical

784 measurement techniques are still prone to errors in data acquisition as well as during the inverse

785 algorithm extraction of optical parameters, thus preventing them from achieving full potential in

786 assessing maturity and quality of fruits and vegetables.

787 The softening of apples during postharvest storage is often accompanied with the structural

788 changes in the fruit tissues and their optical properties. In studying the relationship between the

789 optical properties of apples and the cell structures and firmness, Cen et al. (2013) reported that

790 during the accelerated softening of apples at room temperature, the reduced scattering coefficient

791 for the measured apples of 'Golden Delicious' and 'Granny Smith' varieties for the spectral

792 region of 500-800 $\mathrm{nm}$ showed a consistent pattern of decrease over a period of 30 days, while the 
change of the absorption coefficient was more complex. They further reported that the absorption and reduced scattering coefficients at $675 \mathrm{~nm}$, which corresponds to chlorophyll absorption, were strongly correlated with tissue firmness as well as the area or diameter of tissue cells. This is because the decrease of firmness during the accelerated softening is also accompanied with a

797 decrease in the chlorophyll content. Eccher Zerbini et al. (2006, 2011, 2015) developed

798 mathematical models relating the softening of apples, mangoes, and nectarines with the 799 absorption coefficient at $540 \mathrm{~nm}$ and $670 \mathrm{~nm}$.

In using a SR sensing probe to measure the optical properties of dried apple slices, Nguyen

801 Do Trong et al. (2014b) reported that the scattering coefficient was related to the processing condition, microstructure and textural quality. Rizzolo et al. $(2011 ; 2014 b)$ also reported that the absorption coefficient of 'Cripps Pink' and 'Golden Delicious' apples at $670 \mathrm{~nm}$ measured at harvest could be used to classify raw and dried apple rings for different quality grades.

Table 1. Assessment of maturity and postharvest quality of fruits and vegetables by using optical measurement techniques

\begin{tabular}{|c|c|c|c|}
\hline Product & $\begin{array}{l}\text { Maturity/Quality } \\
\text { Parameter* }\end{array}$ & $\begin{array}{l}\text { Measuring } \\
\text { Technique** }^{*}\end{array}$ & Reference \\
\hline Apple (Fresh) & $\begin{array}{l}\text { Firmness, SSC, anthocyanins, } \\
\text { chlorophyll, carotenoids, starch } \\
\text { index, softening, sensory } \\
\text { profile }\end{array}$ & IS, SR, TR & $\begin{array}{l}\text { Barzaghi et al. (2009); Cen et } \\
\text { al. (2013); Nguyen Do Trong et } \\
\text { al. (2014a); Qin et al. (2009); } \\
\text { Rizzolo et al. (2010b, 2014a); } \\
\text { Sun et al. (2017); Van Beers et } \\
\text { al. (2017b); Vanoli et al. (2011, } \\
\text { 2015) }\end{array}$ \\
\hline $\begin{array}{l}\text { Apple (dried or } \\
\text { processed) }\end{array}$ & $\begin{array}{l}\text { Hardness, firmness, elasticity, } \\
\text { crispness, snapping work, } \\
\text { browning index, flesh color, } \\
\text { porosity }\end{array}$ & SR, TR & $\begin{array}{l}\text { Nguyen Do Trong et al. } \\
\text { (2014b); Rizzolo et al. (2011, } \\
\text { 2014b) }\end{array}$ \\
\hline Banana & Firmness, SSC, ripeness & SR & Adebayo et al. (2016) \\
\hline Kiwifruit & Firmness, SSC, acidity & TR & Valero et al. (2004) \\
\hline Mango & Firmness, pulp color, softening & TR & $\begin{array}{l}\text { Eccher Zerbini et al. (2015); } \\
\text { Pereira et al. (2010); Spinelli et } \\
\text { al., (2012) }\end{array}$ \\
\hline Nectarine & Firmness, softening & TR & $\begin{array}{l}\text { Eccher Zerbini et al. (2006, } \\
\text { 2011); Rizzolo et al. (2010a); } \\
\text { Tijskens et al. (2007a, 2007b) }\end{array}$ \\
\hline Peach & Firmness, SSC & SR, TR & $\begin{array}{l}\text { Cen et al. (2012b); Rizzolo et } \\
\text { al. (2013) }\end{array}$ \\
\hline
\end{tabular}




\begin{tabular}{llll}
\hline Pear & Firmness, SSC, softening & IS, SR, TR & $\begin{array}{l}\text { Adebayo et al. (2017); He et al. } \\
\text { (2016); Nicolai et al. (2008); }\end{array}$ \\
\hline Tomato & $\begin{array}{l}\text { Firmness, SSC, surface color, } \\
\text { flesh color, ripeness }\end{array}$ & SR & $\begin{array}{l}\text { Huang et al. (2018); Qin and Lu } \\
\text { (2008); Zhu et al. (2015) }\end{array}$ \\
\hline
\end{tabular}

* SSC =soluble solids content. ** IS=integrating sphere, $\mathrm{SR}=$ spatially resolved, $\mathrm{SFD}=$ spatial-frequency domain,

TR=time-resolved.

809

\subsection{Defect detection}

Fresh fruits and vegetables are susceptible to a variety of physiological and pathological

812 disorders and mechanical damage during growth, harvest and postharvest handling and storage.

813 Surface defects are relatively easy to detect, while many internal defects still cannot be

814 effectively detected by using the existing optical techniques. Products with defects, either

815 external or internal, tend to have poor marketability and could be rejected by consumers. Hence,

816 it is critical that defective fresh products, especially those with internal defects, be removed or

817 separated during postharvest packing operations. Over the years, many optical techniques (e.g.,

818 Vis/NIR, fluorescence imaging, hyper- and multi-spectral imaging, X-ray imaging, and magnetic

819 resonance imaging) have been used for detecting defects of fruits and vegetables (Lu et al., 2017;

820 Lu and Lu, 2017). For instance, Vis/NIR spectroscopy is now being used in some fruit

821 packinghouses for detecting and segregating fruit with internal defect. However, the commercial

822 Vis/NIR systems still cannot fully meet industry needs because of high false positive/negative

823 rates. Hence, new, more effective inspection technologies are especially needed for internal

824 defect detection.

825 Physiological disorders often cause changes in the chemical and structural properties of

826 products, which would subsequently induce changes in the optical absorption and scattering

827 properties. For instance, internal browning is a common symptom for apple and many other

828 fruits. Apples with internal browning were found to have higher values for the absorption 
coefficient at $750 \mathrm{~nm}$ and lower values for the reduced scattering coefficient at the same wavelength (Vanoli et al., 2009). Due to its ability of penetrating tissues at greater depth, TS technique has been used to detect internal browning and/or internal bleeding of apples, nectarines, and plums (Lurie et al., 2011; Vangdal et al., 2012; Vanoli et al., 2009, 2012). Mealiness alters the cellulosic structure of apple tissues and hence the optical properties. It was thus feasible to differentiate mealy apples from normal ones based on the absorption and reduced scattering coefficients (Vanoli et al., 2009). Likewise, water-cored apples were found to have higher values for the absorption coefficient at $790 \mathrm{~nm}$ and lower values for the reduced scattering coefficient (Vanoli et al., 2009). Studies also showed that diseased onions showed significantly different absorption and scattering characteristics compared to normal onion tissues (Wang et al., 2014). Table 2 lists some recent studies on using the various optical measuring techniques for detecting defects for a variety of fruits and vegetables. While these studies have demonstrated that absorption and reduce scattering coefficients can be used for differentiating normal and defective tissues, there still exist considerable challenges in implementing SR, TR or SFD for real-time, practical inspection of fruits and vegetables for internal defects. First, these techniques are still too slow to be suitable for real-time sorting and grading. Second, both SR and TR techniques are not suitable for detecting defects that are localized or deep inside fruit or vegetable products. TR technique allows greater penetration of light into tissues, but its measurement can only interrogate a small section of the sample tissue. While SFD technique has potential for wide-area, 3D mapping of optical properties for horticultural products, it has limited capabilities of imaging tissues at no more than 1-2 $\mathrm{mm}$ deep.

Table 2. Detection of defects of fruits and vegetables using optical absorption and scattering properties.

\begin{tabular}{llll}
\hline Product & Type of Defect & $\begin{array}{l}\text { Measuring } \\
\text { Technique* }\end{array}$ & Reference \\
\hline
\end{tabular}




\begin{tabular}{|c|c|c|c|}
\hline \multirow[t]{4}{*}{ Apple } & Bruising & IS, SR, SFD & $\begin{array}{l}\text { Anderson et al., (2007); } \\
\text { Lu et al. (2010); Zhang } \\
\text { et al. (2017b) }\end{array}$ \\
\hline & Internal browning & SFD, TR & $\begin{array}{l}\text { Hu et al. }(2016) \text {; Lurie } \\
\text { et al. }(2011) \text {; Vanoli et } \\
\text { al. }(2009,2012) \text {; }\end{array}$ \\
\hline & Mealiness & TR & $\begin{array}{l}\text { Valero et al. (2005); } \\
\text { Vanoli et al. (2009) }\end{array}$ \\
\hline & Watercore & TR & Vanoli et al. (2009) \\
\hline Blueberry & Bruising & IS & $\begin{array}{l}\text { Zhang et al. (2017a, } \\
\text { 2019) }\end{array}$ \\
\hline Cucumber (pickling) & Bruising & SR & Lu et al. (2011) \\
\hline Nectarine & $\begin{array}{l}\text { Internal bleeding, internal } \\
\text { browning }\end{array}$ & TR & Lurie et al. (2011) \\
\hline Onion & Sour skin, neck rot & IS & Wang et al. (2014) \\
\hline Orange & Decay & SR & Lorente et al. (2015) \\
\hline Pear & Brown heart & TR & $\begin{array}{l}\text { Eccher Zerbini et al. } \\
(2002)\end{array}$ \\
\hline Plum & Internal browning & TR & Vangdal et al. (2012) \\
\hline
\end{tabular}

* IS=integrating sphere, $\mathrm{SR}=$ spatially resolved, $\mathrm{SFD}=$ spatial-frequency domain, TR=time-resolved.

\section{Issues and Challenges}

Over the past 15 years, we have seen significant research efforts in the development and application of new SR, SFD, and TR techniques, along with IS-IAD, for optical characterization

857 of horticultural and food products. While these emerging techniques offer new opportunities for

858 quality and safety assessment of horticultural and food products, there still exist considerable

859 issues and challenges in using these techniques due to increased sophistication and investment in

860 instrumentation and algorithms, compared to conventional spectroscopic techniques. First, many

861 of these techniques are based on the diffusion approximation theory (except for data-based models or MC libraries discussed in Section 2). As discussed earlier, the diffusion approximation theory is only applicable to samples, in which light scattering is dominant over absorption (i.e.,

$864 \mu_{s} \gg \mu_{a}$ ). This condition is not always met satisfactorily as many biological materials like fruits

865 and vegetables show strong absorption at specific wavelengths or spectral regions due to 
biological chromophores (anthocyanins, carotenoids, chlorophyll, water, etc.). For these spectral regions, the diffusion theory would introduce large errors or is completely inadequate. Second, accurate estimations of optical absorption and scattering properties are also hindered by our ability of acquiring reliable, high-quality spatially- or time-resolved reflectance signals from horticultural samples, which are sensitive to noise and imperfect sample conditions (e.g.,

871 irregular geometry, limited sample dimensions, presence of local defects or abnormalities, etc.).

872 With SR techniques, a small, collimated, and normally-incident light source is critical to proper

873 measurement of spatially-resolved reflectance. However, it is difficult to meet all the

874 requirements in actual application situations. Likewise, with TR techniques, the equipment used

875 to generate short laser pulses and acquire the reflected signals over the time scale of $10^{-12} \mathrm{~s}$ to $10^{-}$

$876{ }^{9} \mathrm{~s}$ are complex and expensive. Accurate measurements of optical properties are further

877 complicated by the fact that many fruits and vegetables are heterogeneous in structure and are of

878 irregular shape or uneven surface. Specifically, the surface layer (i.e., skin or rind) of

879 horticultural products has distinct optical properties and its presence could cause problems for 880 the measurement of sublayer optical properties, which are usually of major interest for quality 881 assessment (Saeys et al., 2008; Van Beers et al., 2017b). Hence, it is desirable or even necessary 882 to consider the heterogeneity properties in measuring fruit and vegetable products. Preliminary 883 efforts have been made on using SR and SFD techniques to measure the optical properties of 884 fruit skin and flesh by treating them as two layers of homogeneous tissues (Cen and Lu, 2009;

885 Hu et al., 2019; Wang et al., 2017a). However, considerably more challenges would be 886 encountered in obtaining acceptable estimations of the optical properties of individual layers, due 887 to the increased number of unknown optical parameters and much more complicated 888 mathematical models for two-layer turbid media. Moreover, in all SR, TR and SFD systems, the 
acquired reflectance signals are closely related to the instrument response. It is thus important

890

891

892

893

894

895

896

897

898

899

900

901

902

903

904

905

906

907

908

909

910

911

that the reflectance signals be properly corrected or calibrated, before being used for inverse estimation of optical properties. Currently, no standard procedures have been established for calibrating these optical systems. Consequently, the optical measurement results are influenced, to a great extent, by the calibration procedure. Many a time, reference samples of known optical properties are needed during the calibration process. Proper procedures for preparation and selection of reference samples are thus critical to the calibration of an optical system.

Furthermore, many SR, TR and SFD measurement configurations require contact of the light source and/or detection probe with the sample to be measured. The measurements are not carried out in real time and/or rapidly. For horticultural and food products, fast and noncontact measurements are often needed or desirable. Hence, much research is still needed in further development and/or improvement of these emerging optical property measurement techniques for better assessment of horticultural and food products. Finally, proper preprocessing procedures for the acquired reflectance data are important for the inverse estimation of optical parameters. Different preprocessing treatment methods and procedures can have significant ramifications on the estimation of optical parameters (Cen and Lu, 2010, 2011; Hu et al., 2018, 2019; Wang et al., 2017a, 2017b).

Overall, the inverse approach to optical property estimation is a complicated process, and it relies on an appropriate mathematical model, precise instrumentation setup and calibrations, and rigorous inverse algorithms. Large estimation errors for the optical parameters could be incurred, if the measuring system is not carefully calibrated, procedures for the inverse algorithm are not properly implemented, or samples are of irregular shape or contain defective or irregular tissue spots within the area of measurement. The presence of these issues and challenges also provides 
912 opportunities for further research for these emerging techniques. Further research should also be 913 directed at the development of low-cost, portable or even miniaturized optical measuring systems

914 that can perform optical property measurements in real time, in the field, and under online 915 situations.

916 In view of the more complicated, time-consuming procedures for inverse estimation of the 917 optical properties, researchers have also proposed simpler and faster direct approaches to analyze 918 the reflectance data acquired from SR and SFD techniques for quality and maturity assessment 919 and defect detection of fruits and vegetables. For instance, simple empirical mathematical 920 models or scattering image features have been used to describe the 1-D scattering profiles or 2-D 921 scattering images acquired by SR technique in FOP (Huang et al., 2018c), MCI (Baranyai and 922 Zude, 2009; Lu, 2004; Mollazade et al., 2013; Peng and Lu, 2005, 2006; Qing et al., 2008), or 923 HSI modes (Huang and Lu, 210; Peng and Lu, 2008), which were found to correlate well with 924 quality attributes such as fruit firmness and SSC. For the SFD technique, SIRI has been used as a 925 new imaging modality for detecting subsurface defects of apple, peach, and other fruits (Li et al., 926 2018; Lu et al., 2016a; Lu and Lu, 2017; Sun et al., 2019). However, these direct approaches are

927 highly dependent on instrumentation setup and the models developed for different systems are 928 generally not interchangeable and cannot be compared directly for different studies.

929 6. Conclusions

930 Optical absorption and scattering properties are directly related to the chemical and structural 931 properties of fruits and vegetables, and thus are useful for evaluating maturity, quality and 932 defects of products. Over the past 15 years, several emerging optical property measuring 933 techniques have been made available for assessing fruits and vegetables and other food products. 934 IS-IAD technique is widely used as a standard method for measuring optical absorption and 
935 scattering properties. The technique is, however, destructive and requires careful preparation of

936 samples with specific dimensions for measurement. SR technique is relatively simple in

937 instrumentation, low in cost and faster in measurement. Thus, different SR sensing

938 configurations have been developed for measuring fruits and vegetables. However, accurate

939 estimation of optical absorption and reduced scattering coefficients by SR technique is still

940 challenging, due to measurement errors in SR reflectance and challenges in the inverse algorithm

941 implementation. TR technique, on the other hand, can interrogate tissues at greater depth, which

942 is important for detection of internal quality or defects in horticultural products. However, the

943 technique needs sophisticated and expensive instrumentation, which could limit it for wide

944 practical applications in quality inspection of fruits and vegetables. SFD technique offers the

945 unparalleled capability and potential of measuring and mapping optical properties of fruit and

946 vegetable products, but its imaging depth and resolution is still limited. Considerable research is

947 thus needed in both hardware and software (i.e., mathematical modeling and data processing) for

948 improving accuracy and reliability in measurement of the optical properties by these emerging

949 optical techniques. Moreover, research should also be devoted to the development of low-cost,

950 portable or miniaturized optical property measurement systems and for implementing these

951 emerging techniques for real-time, online applications for quality assessment of horticultural

952 products. 


\section{References}

Adebayo, S.E., Hashim, N., Abdan, K., Hanafi, M., Mollazade, K., 2016. Prediction of quality attributes and ripeness classification of bananas using optical properties. Scientia Hort. 212, 171-182.

Adebayo, S.E., Hashim, N., Reich, O., Regen, C., Munzberg, M., Abdan, K., Zude-Sasse, M., 2017. Using absorption and reduced scattering coefficients for non-destructive analyses of fruit flesh firmness and soluble solids content in pear (Pyrun communis 'Conference') - An update when using diffusion theory. Postharvest Biol. Technol. 130, 56-63.

Aernouts, B., 2014. Optical Characterization of Milk. Ph.D. thesis, KU Leuven, Belgium.

Aernouts, B., Erkinbaev, C., Watté, R., Van Beers, R., Nguyen Do Trong, N., Nicolaï, B., Saeys, W., 2015. Estimation of bulk optical properties of turbid media from hyperspectral scatter imaging measurements: metamodeling approach. Opt. Express 23, 26049-26063.

Aernouts, B., Watté, R., Van Beers, R., Delport, F., Merchiers, M., De Block, J., Lammertyn, J., Saeys, W., 2014. Flexible tool for simulating the bulk optical properties of polydisperse spherical particles in an absorbing host: Experimental validation. Opt. Express 22, 2022320238.

Aernouts, B., Zamora-Rojas, E., Van Beers, R., Watté, R., Wang, L., Tsuta, M., Lammertyn, J., Saeys, W., 2013. Supercontinuum laser based optical characterization of Intralipid® phantoms in the 500-2250 nm range. Opt. Express 26, 32450-32467.

Anderson, E.R., Cuccia, D.J, Durkin, A.J., 2007. Detection of bruises on Golden Delicious apples using spatial-frequency-domain imaging. Proceedings of the SPIE 6430, 64301O, SPIE, Bellingham, WA, USA.

Baranyai, L., Zude, M., 2009. Analysis of laser light propagation in kiwifruit using backscattering imaging and Monte Carlo simulation. Comput. Electron. Agric. 69, 33-39.

Barzaghi, S., Vanoli, M., Cremonesi, K., Cotellino, G., Torreggiani, D., Rizzolo, A., Grassi, M., Spinelli, L., Torricelli, A., 2009. Outer product analysis applied to time-resolved reflectance spectroscopy (TRS) and NIR reflectance spectra of apples. Proceedings of $14^{\text {th }}$ International Conference on NIR Spectroscopy 213-218. IM Publications LLP, Chichester.

Bashkatov, A.N., Genina, E.A., Kochubey, V.I., Tuchin, V.V., 2005. Optical properties of human skin, subcutaneous and mucous tissues in the wavelength range from 400 to $2000 \mathrm{~nm}$. Journal of Physics D: Applied Physics, 38, 2543-2555.

Birth, G.S., 1978. The light scattering properties of foods. J. Food Sci. 16, 916-925.

Birth, G.S., 1982. Diffuse thickness as a measure of light scattering. Appl. Spectros., 36, 675682.

Birth, G.S., Davis, C.E., Townsend, W.E., 1978. The scatter coefficient as a measure of pork quality. J. Animal Sci. 46, 639-645.

Bodenschatz, N., Brandes, A., Liemert, A., Kienle, A., 2014. Sources of errors in spatial frequency domain imaging of scattering media. J. Biomed. Opt. 19, 071405.

Cen, H., Lu, R., 2009. Quantification of the optical properties of two-layer turbid materials using a hyperspectral imaging-based spatially-resolved technique. Appl. Opt. 48, 5612-5623.

Cen, H., Lu, R., 2010. Optimization of the hyperspectral imaging-based spatially-resolved system for measuring the optical properties of biological materials. Opt. Express 18, 1741217432 . 
Cen, H., Lu, R., Dolan, K., 2010. Optimization of inverse algorithm for estimating optical properties of biological materials using spatially-resolved diffuse reflectance. Inverse Prob. Sci. Eng. 18, 853-872.

Cen, H., Lu, R., Mendoza, F., 2012a. Analysis of absorption and scattering spectra for assessing the internal quality of apple fruit. Acta Hortic. 945, 181-188.

Cen, H., Lu, R., Mendoza, F.A., Ariana, D.P., 2012b. Assessing multiple quality attributes of peaches using optical absorption and scattering properties. Trans. ASABE 55, 647-657.

Cen, H., Lu, R., Mendoza, F., Beaudry, R.M., 2013. Relationship of the optical absorption and scattering properties with mechanical and structural properties of apple tissue. Postharvest Biol. Technol. 85, 30-38.

Clément, A., Dorais, M., Vernon, M., 2008. Nondestructive measurement of fresh tomato lycopene content and other physicochemical characteristics using visible-NIR spectroscopy. J. Agric. Food Chem. 56, 9813-9818.

Cubeddu, R., D’Andrea, C., Pifferi, A., Taroni, P., Torricelli, A., Valentini, G., Dover, C., Johnson, D., Ruiz-Altisent, M., Valero, C., 2001a. Nondestructive quantification of chemical and physical properties of fruits by time-resolved reflectance spectroscopy in the wavelength range of 650-1000 nm. Appl. Opt. 40, 538-543.

Cubeddu, R., D’Andrea, C., Pifferi, A., Taroni, P., Torricelli, A., Valentini, G., Ruiz-Altisent, M., Valero, C., Ortiz, C., Dover, C., Johnson, D., 2001b. Time-resolved reflectance spectroscopy applied to the nondestructive monitoring of the internal optical properties in apples. Appl. Spectros. 55, 1368-1374.

Cuccia, D.J., Bevilacqua, F., Durkin, A.J., Tromberg, B.J., 2005. Modulated imaging: quantitative analysis and tomography of turbid media in the spatial-frequency domain. Opt. Lett. 30, 1354-1356.

Cuccia, D.J., Bevilacqua, F., Durkin, A.J., Ayers, F.R., Tromberg, B.J., 2009. Quantitation and mapping of tissue optical properties using modulated imaging. J. Biomed. Opt. 14, 024012.

Doornbos, R.M., Lang, R., Aalders, M.C., Cross, F.W., Sterenborg, H., 1999. The determination of in vivo human tissue optical properties and absolute chromophore concentrations using spatially resolved steady-state diffuse reflectance spectroscopy. Phys. Med. Biol. 44, 967981.

Du, H., Voss, K.J., 2004. Effects of point-spread function on calibration and radiometric accuracy of CCD camera. Appl. Opt. 43, 665-670.

Eccher Zerbini, P., Grassi, M., Cubeddu, R., Pifferi, A., Torrecilli, A., 2002. Nondestructive detection of brown heart in pears by time-resolved reflectance spectroscopy. Postharvest Biol. Technol. 25, 87-97.

Eccher Zerbini, P., Vanoli, M., Grassi, M., Rizzolo, A., Fibiani, M., Cubeddu, R., Pifferi, A., Spinelli, L., Torricelli, A., 2006. A model for the softening of nectarines based on sorting fruit at harvest by time-resolved reflectance spectroscopy. Postharvest Biol. Technol. 39, 223-232.

Eccher Zerbini, P., Vanoli, M., Lovati, F., Spinelli, L., Torricelli, A., Rizzolo, A., Lurie, S., 2011. Maturity assessment at harvest and predition of softening in a late maturing nectarine cultivar after cold storage. Postharvest Biol. Technol. 62, 275-281.

Eccher Zerbini, P., Vanoli, M., Rizzolo, A., Grassi, M., de Azevedo Pimentel, R.M., Spinelli, L., Torricelli, A., 2015. Optical properties, ethylene production and softening in mango fruit. Postharvest Biol. Technol. 101, 58-65. 
Erkinbaev, C., Herremans, E., Nguyen Do Trong, N., Jakubczyk, E., Verboven, P., Nicolaï, B., Saeys, W., 2014. Contactless and non-destructive differentiation of microstructures of sugar foams by hyperspectral scatter imaging. Innov. Food Sci. Emerg. Technol. 24, 131-137.

Fabbri, F., Franceschini, M.A., Fantini, S., 2003. Characterization of spatial and temporal variations in the optical properties of tissuelike media with diffuse reflectance imaging. Appl. Opt. 42, 3063-3072.

Fang, Z.H., Fu, X.P., He, X.M., 2016. Investigation of absorption and scattering characteristics of kiwifruit tissue using a single integrating sphere system. J. Zhejiang Univ.-SCIENCE B 17, 484-492.

Farrell, T.J., Patterson, M.S., Wilson, B., 1992. A diffusion theory model of spatially resolved, steady-state diffuse reflectance for the noninvasive determination of tissue optical properties in vivo. Med. Phys. 19, 879-888.

Hale, G.M., Querry, M.R., 1973. Optical constants of water in the 200-nm to $200-\mu \mathrm{m}$ wavelength region. Appl. Optics 12, 555-563.

Hjalmarsson, P., Thennadil, S.N. 2007. Spatially resolved in vivo measurement system for estimating the optical properties of tissue in the wavelength range 1000-1700 nm. In: Schweitzer, D., Fitzmaurice, M. (Eds.). Proceedings of SPIE 6628, 662805.

Hjalmarsson, P., Thennadil, S. N. 2008. Determination of glucose concentration in tissue-like material using spatially resolved steady-state diffuse reflectance spectroscopy. In: Tuchin, V.V., Wang, L.V. (Eds.). Proceedings of SPIE 6855, 685508.

He, X., Fu, X., Li, T., Rao, X., 2018. Spatial frequency domain imaging for detecting bruises of pears. J. Food Meas. Charact. 12, 1266-1273.

He, X., Fu, X., Rao, X., Fu, F., 2017. Nondestructive determination of optical properties of a pear using spatial frequency domain imaging combined with phase-measuring profilometry. Appl. Opt. 56, 8207-8215.

He, X., Fu, X., Rao, X., Fang, Z., 2016. Assessing firmness and SSC of pears based on absorption and scattering properties using an automatic integrating sphere system from 400 to $1150 \mathrm{~nm}$. Postharvest Biol. Technol. 121, 62-70.

Hebden, J.C., Gibson, A., Austin, T., Yusof, R.M., Everdell, N., Delpy, D.T., Arridge, S.R., Meek, J. H., Wyatt, J.S., 2004. Imaging changes in blood volume and oxygentation in the newborn infant brain using three-dimensional optical tomography. Phys. Med. Biol. 49, 1117-1130.

$\mathrm{Hu}, \mathrm{D} ., \mathrm{Fu}, \mathrm{X}$., He, X., Ying, Y., 2016. Noncontact and wide-field characterization of the absorption and scattering properties of apple fruit using spatial-frequency domain imaging. Sci. Rep. 6, 37920.

Hu, D., Lu, R., Ying, Y., 2018. A two-step parameter optimization algorithm for improving estimation of optical properties using spatial frequency domain imaging. J. Quan. Spec. Rad. Transfer 207, 32-40.

Hu, D., Lu, R., Ying, Y., 2019. A stepwise method for estimating optical properties of two-layer turbid media from spatial-frequency domain reflectance. Opt. Express 27, 1124-1141.

Huang, M., Lu, R., 2010. Optimal wavelength selection for hyperspectral scattering prediction of apple firmness and soluble solids content. Trans. ASABE 53, 1175-1182.

Huang, Y., Lu, R., Chen, K., 2017. Development of a multichannel hyperspecral imaging probe for property and quality assessment of horticultural products. Postharvest Biol. Technol. 133, 88-97. 
Huang, Y., Lu, R., Chen, K., 2018a. Prediction of firmness parameters of tomatoes by portable visible and near-infrared spectroscopy. J. Food Eng. 222, 185-198.

Huang, Y., Lu, R., Chen, K., 2018b. Quality assessment of tomato fruit by optical absorption and scattering properties. Postharvest Biol. Technol. 143, 78-85.

Huang, Y., Lu, R., Chen, K., 2018c. Prediction of tomato firmness using spatially-resolved spectroscopy. Postharvest Biol. Technol. 140, 18-26.

Jacquez, J.A., Kuppenheim, H.F., 1955. Theory of the integrating sphere. J. Opt. Soc. America. 55, 460-470.

Kienle, A., Patterson, M.S., 1997. Improved solutions of the steady-state and the time-resolved diffusion equations for reflectance from a semi-infinite turbid medium. J. Opt. Soc. America A 14, 246-254.

Lancaster, J.E., Grant, J.E., Lister, C.E., Taylor, M.C., 1994. Skin color in apples - Influence of copigmentation and plastid pigments on shade and darkness of red color in five genotypes. J. Am. Soc. Hort. Sci. 119, 63-69.

Langerholc, J., 1982. Beam broadening in dense scattering media. Appl. Opt. 21, 1593-1598.

Leyre, S., Durinck, G., Van Giel, B., Saeys, W., Hofkens, J., Deconinck, G., Hanselaer, P., 2012. Extended adding-doubling method for fluorescent applications. Opt. Express 20, 1785617872.

Li, R., Lu, Y., Lu, R., 2018. Structured illumination reflectance imaging for detection of subsurface tissue bruising in apples. Trans. ASABE 61, 809-819.

López-Maestresalas, A., Aernouts, B., Van Beers, R., Arazuri, S., Jarén, C., de Baerdemaeker, J., Saeys, W., 2015. Bulk optical properties of potato flesh in the 500-1900 nm range. Food Bioprocess Technol. 9, 463-470.

Lorente, D., Aleixos, N., Gómez-Sanchis, J., Cubero, S., Blasco, J., 2013. Selection of optimal wavelength features for decay detection in citrus fruit using the ROC curve and neural networks. Food Bioprocess Technol. 6, 530-541.

Lorente, D., Zude, M., Idler, C., Gómez-Sanchis, J., Blasco, J., 2015. Laser-light backscattering imaging for early decay detection in citrus fruit using both a statistical and a physical model. J. Food Eng. 154, 76-85.

Lu, R., 2004. Multispectral imaging for predicting firmness and soluble solids content of apple fruit. Postharvest Biol. Technol. 31, 147-157.

Lu, R., 2008. Quality evaluation of fruit by hyperspectral imaging. In: Sun, D.W. (Eds.), Computer Vision Technology for Food Quality Evaluation. Academic Press, Cambridge, MA, USA, pp. 319-348.

Lu, R. (Ed.), 2016. Light Scattering Technology for Food Property, Quality and Safety Assessment. CRC Press, Boca Raton, FL, USA.

Lu, R., Ariana, D.P., Cen, H., 2011. Optical absorption and scattering properties of normal and defective picking cucumber for 700-1000 nm. Sens. \& Instrumen. Food Qual. 5, 51-56.

Lu, R., Cen, H., Huang, M., Ariana, D.P., 2010. Spectral absorption and scattering properties of normal and bruised apple tissue. Trans. ASABE 53, 263-269.

Lu, Y., 2018. Development of Strucutred Illumination Reflectance Imaging Technique as a New Modality for Enhanced Defect Detection of Apples. Ph.D. dissertation, Michigan State University, East Lansing, MI, USA, 253pp.

Lu, Y., Huang, Y., Lu, R., 2017. Innovative hyperspectral imaging-based techniques for quality evaluation of fruits and vegetables: A review. Appl. Sci. 7, 189. 
Lu, Y., Li, R., Lu, R., 2016a. Structured-illumination reflectance imaging (SIRI) for enhanced detection of fresh bruises in apples. Postharvest Biol. Technol. 117, 89-93.

Lu, Y., Li, R., Lu, R., 2016b. Fast demodulation of pattern images by spiral phase transform in structured-illumination reflectance imaging for detection of bruises in apples. Comp. Elec. Agric. 127, 652-658.

Lu, Y., Li, R., Lu, R., 2016c. Gram-Schmidt orthonormalization for retrieval of amplitude images under sinusoidal patterns of illumination. Appl. Opt. 55, 6866-6873.

Lu, Y., Lu, R., 2017a. Non-destructive defect detection of apples by spectroscopic and imaging technologies: A review. Trans. ASABE 60, 1765-1790.

Lu, Y., Lu, R. 2017b. Development of a multispectral structured-illumination reflectance imaging (SIRI) system and its applications to bruise detection of apples. Trans. ASABE 60, 1379-1389.

Lurie, S., Vanoli, M., Daga, A., Weksler, A., Lovati, F., Eccher Zerbini, P., Spinelli, L., Torricelli, A., Feng, J., Rizzolo, A., 2011. Chilling injury in stored nectarines and its detection by time-resolved reflectance spectroscopy. Postharvest Biol. Technol. 59, 211-218.

Malsan, J., Gurjar, R., Wolf, D., Vishwanath, K., 2014. Extracting optical properties of turbid media using radially and spectrally resolved diffuse reflectance. Proc. SPIE. 8936, 893615, SPIE, Bellingham, WA, USA.

Marquet, P., Bevilacqua, F., Depeursinge, C., Dehaller, E.B., 1995. Determination of reduced scattering and absorption-coefficients by a single charge-coupled-device array measurement. 1. comparison between experiments and simulations. Opt. Eng. 34, 2055-2063.

Martelli, F., Del Bianco, S., Ismaelli, A., Zaccanti, G., 2010. Light Propagation through Biological Tissue and Other Diffusive Media. SPIE Press, Bellingham, WA, USA.

Merzlyak, M.N., Solovchenko, A.E., Gitelson, A.A., 2003. Reflectance spectral features and non-destructive estimation of chlorophyll, carotenoid and anthocyanin content in apple fruit. Postharvest Biol. Technol. 27, 197-211.

Mollazade, K., Arefi, A., 2017. Optical analysis using monochromatic imaging-based spatiallyresolved technique capable of detecting mealiness in apple fruit. Sci. Hortic. 225, 589-598.

Mollazade, K., Omid, M., Tab, F.A., Kalaj, Y.R., Mohtasebi, S.S., Zude, M., 2013. Analysis of texture-based features for predicting mechanical properties of horticultural products by laser light backscattering imaging. Comp. Electr. Agric. 98, 34-45.

Nguyen Do Trong, N., Erikinbaev, C., Tsuta, M., De Baerdemaeker, J., Nicolaï, B.M., Saeys, W., 2014a. Spatially resolved diffuse reflectance in the visible and near-infrared wavelength range for non-destructive quality assessment of 'Braeburn' apples. Postharvest Biol. Technol. 91, 39-48.

Nguyen Do Trong, N., Rizzolo, A., Herremans, E., Vanoli, M., Cortellino, G., Erkinbaev, C., Tsuta, M., 2014b. Optical properties-microstructure-texture relationships of dried apple slices: Spatially resolved diffuse reflectance spectroscopy as a novel technique for analysis and process control. Innovative Food Sci. Emerg. Technol. 21, 160-168.

Nicolaï, B.M., Beullens, K., Bobelyn, E., Peirs, A., Saeys, W., Theron, K.I., Lammertyn, J., 2007. Nondestructive measurement of fruit and vegetable quality by means of NIR spectroscopy: A review. Postharvest Biol. Technol. 46, 99-118.

Nicolaï, B.M., Verlinden, B.E., Desmet, M., Saevels, S., Saeys, W., Theron, K., Cubeddu, R., Pifferi, A, Torricelli, A., 2008. Time-resolved and continuous wave NIR reflectance spectroscopy to predict soluble solids content and firmness of pear. Postharvest Biol. Technol. 47, 68-74. 
Patterson, M.S., Chance, B., Wilson, B.C., 1989. Time resolved reflectance and transmittance for the non-invasive measurement of tissue optical properties. Appl. Opt. 28, 2331-2336.

Patterson, M.S., Moulton, J.D., Wilson, B.C., Berndt, K.W., Lakowicz, J.R. 1991. Frequencydomain reflectance for the determination of the scattering and absorption properties of tissue. Appl. Opt. 30, 4474-4476.

Peng, Y., Lu, R., 2005. Modeling multispectral scattering profiles for prediction of apple fruit firmness. Trans. ASABE 48, 235-242.

Peng, Y., Lu, R., 2006. Improving apple fruit firmness predictions by effective correction of multispectral scattering images. Postharvest Biol. Technol. 41, 266-274.

Peng, Y., Lu, R., 2007. Prediction of apple fruit firmness and soluble solids content using characteristics of multispectral scattering imaging. J. Food Eng. 82, 142-152.

Peng, Y., Lu, R., 2008. Analysis of spatially resolved hyperspectral scattering images for assessing apple fruit firmness and soluble solids content. Postharvest Biol. Technol. 48(1), 52-62.

Pereira, T., Tijskens, L.M.M., Vanoli, M., Rizzolo, A., Eccher Zerbini, P., Torricelli, A., Spinelli, L., Filgueiras, H., 2010. Assessing the harvest maturity of Brazilian mangoes. Acta Hortic. 880, 269-276.

Pickering, J.W., Prahl, S.A., van Wieringen, N., Beek, J.F., Sterenborg, H.J.C.M., van Gemert, M.J.C., 1993. Double-integrating-sphere system for measuring the optical properties of tissue. Appl. Opt. 32, 399-410.

Pifferi, A., Taroni, P., Torricelli, A., Messina, F., Cubeddu, R., 2003. Four-wavelength timeresolved optical mammography in the 680-980 nm range. Opt. Lett. 28 1138-40.

Pilz, M., Honold, S., Kienle, A., 2008. Determination of the optical properties of turbid media by measurements of the spatially resolved reflectance considering the point-spread function of the camera system. J. Biomed. Opt. 13, 054047.

Pogue, B.W., Patterson, M.S., 2006. Review of tissue simulating phantoms for optical spectroscopy, imaging and dosimetry. J. Biomed. Opt. 11, 041102.

Postelmans, A., Aernouts, B., Sayes, W., 2018. Estimation of partical size distributions from bulk scattering spectra: sensivitiy to distribution type and spectral noise. Opt. Express 26, $15015-15038$.

Prahl, S.A., 2011. Everything I Think You Should Know About Inverse Adding-Doubling. https://omlc.org/software/iad/manual.pdf.

Prahl, S.A., 1995. The adding doubling method. In: Welch, A.J., van Gemert, M.J.C. (Eds.), Optical-Thermal Response of Laser Irradiated Tissue, Springer, New York, NY, USA, pp. 101-129.

Prahl, S.A., van Gemert, M. J.C.,Welch, A.J., 1993. Determining the optical properties of turbid media by using the adding-doubling method. Appl. Opt. 32, 559-568.

Qin, J., Lu, R., 2007. Measurement of the absorption and scattering properties of turbid liquid foods using hyperspectral imaging. Appl. Spectr. 61, 388-396.

Qin, J., Lu, R., 2008. Measurement of the optical properties of fruits and vegetables using spatially resolved hyperspectral diffuse reflectance imaging technique. Postharvest Biol. Technol. 49, 355-365.

Qin, J., Lu, R., 2009. Monte Carlo simulation for quantification of light transport features in apples. Comput. Electron Agric. 68, 44-51.

Qin, J., Lu, R., Peng, Y., 2009. Prediction of apple internal quality using spectral absorption and scattering properties. Trans. ASABE 52, 499-507. 
Qing, Z., Ji, B., Zude, M., 2008. Non-destructuve analyses of apple quality parameters by means of laser-induced light backscattering imaging. Postharvest Biol. Technol. 48, 215-222.

Reynolds, L., Johnson, C., Ishimaru, A., 1976. Diffuse reflectance from a finite blood mediumapplications to modeling of fiber optic catheters. Appl. Optics 15, 2059-2067.

Rizzolo, A., Bianchi, G., Vanoli, M., Lurie, S., Spinelli, L., Torricelli, A., 2013. Electronic nose to detect volatile compound profile and quality changes in 'Spring Belle' peach (Prunus persica L.) during cold storage in relation to fruit optical properties measured by timeresolved reflectance spectroscopy. J. Agric. Food Chem., 61, 1671-1685.

Rizzolo, A., Vanoli, M., 2016. Time-resolved technique for measuring optical properties and quality of food. In: Lu, R. (Ed.), Light Scattering Technology for Food Property, Quality and Safety Assessment. CRC Press, Boca Raton, FL, pp. 187-224

Rizzolo, A., Vanoli, P., Bianchi, G., 2014a. Relationship between texture sensory profiles and optical properties measured by time-resolved reflectance spectroscopy during post storage shelf life of 'Braeburn' apples. J. Hort. Res. 22, 113-121.

Rizzolo, A., Vanoli, M., Cortellino, G., Spinelli, L., Contini, D., Herremans, E., Bongaers, E., Nemeth, A., Leitner, M., Verboven, P., Nicolaï, B.M., Torricelli, A., 2014b. Characterizing the tissue of apple air-dried and osmo-air-dried rings by X-CT and OCT and relationship with ring crispness and fruit maturity at harvest measured by TRS. Innovative Food Sci. Emerg. Technol. 24, 121-130.

Rizzolo, A., Vanoli, M., Cortellino, G., Spinelli, L., Torricelli, A., 2011. Quality characteristics of air dried apple rings: Influence of storage time and fruit maturity measured by timeresolved reflectance spectroscopy. Porcedia Food Sci., 1, 216-223.

Rizzolo, A., Vanoli, M., Eccher Zerbini, P., Spinelli, L., Torricelli, A., 2010a. Influence of cold storage time on the softening prediction in "Spring Bright" nectarines. Acta Hortic. 877, 1395-1402.

Rizzolo, A., Vanoli, M., Spinelli, L., Torricelli, A., 2010b. Sensory characteristics, quality and optical properties measured by time-resolved reflectance spectroscopy in stored apples. Postharvest Biol. Technol. 58, 1-12.

Romano, G., Nagle, M., Argyropoulos, D., Muller, J., 2011. Laser light backscattering to monitor moisture content, soluble solid content and hardness of apple tissues during drying. J. Food Eng. 104, 657-662.

Rowe, P.I., Künemeyer, R., McGlone, A., Talele, S., Martinsen, P., Seelye, R., 2014. Relationship between tissue firmness and optical properties of 'Royal Gala' apples from 400 to $1050 \mathrm{~nm}$. Postharvest Biol. Technol. 94, 89-96.

Saeys, W., Velazco-Roa, M.A., Thennadil, S.N., Ramon, H., Nicolaï, B.M., 2008. Optical properties of apple skin and flesh in the wavelength range from 350 to $2200 \mathrm{~nm}$. Appl. Opt. 47, 908-919.

Seifert, R., Zude, M., Spinelli, L., Torricelli, A., 2015. Optical properties of developing pip and stone fruit reveal underlying structural changes. Physiol. Plant. 153, 327-336.

Sharma, M., Hennessy, R., Markey, M.K., Tunnell, J.W., 2014. Verification of a two-layer inverse Monte Carlo absorption model using multiple source-detector separation diffuse reflectance spectroscopy. Biomed. Opt. Express 5, 40.

Simpson, T.W., Poplinski, J.D., Koch, P.N., Allen, J.K., 2001. Metamodels for computer-based engineering design: Survey and recommendations. Eng. Comput. 17, 129-150.

Spinelli, L., Rizzolo, A., Vanoli, M., Grassi, M., Eccher Zerbini, P., de Azevedo Pimentel, R.M., Torricelli, A., 2012. Optical properties of pulp and skin in Brazilian mangoes in the 540-900 
nm spetral region: implication for non-destructive maturiy assessment by time-resolved reflectance spetroscopy. Proceedings of the 3rd CIGR International Conference of Agricultural Engineering (CIGR-AgEng2012), July 8-12, Valencia, Spain.

Sun, J., Kunnemeyer, R., McGlone, A., Rowe, P., 2017. Multispectral scattering imaging and NIR interactance for apple firmness predictions. Postharvest Biol. Technol. 119, 58-68.

Sun, Y., Lu, R., Lu, Y., Tu, K., Pan, L., 2019. Detection of early decay in peaches by structuredillumination reflectance imaging. Postharvest Bio. Technol. (in press)

Tijskens, L.M.M., Eccher Zerbini, P., Schouten, R.E., 2007a. Biological variation in ripening of nectarine. Veg. Crops Res. Bull. 66, 205-212.

Tijskens, L.M.M., Eccher Zerbini, P., Schouten, R.E., Vanoli, M., Jacob, S., Grassi, M., Cubeddu, R., Spinelli, L., Torricelli, A., 2007b. Assessing harvest maturity in nectarines. Postharvest Biol. Technol. 45, 204-213.

Torricelli, A., 2009. Determination of optical properties in turbid media: time-resolved approach. In: Zude, M. (Ed.). Optical Monitoring of Fresh and Processed Agricultural Crops. CRS Press, Boca Raton, FL, USA, pp. 55-81.

Tu, K., Jancsok, P., Nicolaï, B., De Baerdemaeker, J., 2000. Use of laser-scattering imaging to study tomato-fruit quality in relation to acoustic and compression measurements. Int. J. Food Sci. Technol. 35, 503-510.

Tuchin, V.V., 2007. Tissue Optics: Light Scattering Methods and Instruments for Medical Diagnosis. SPIE Press, Bellingham, WA, USA.

Valero, C., Barreiro, P., Ruiz-Altisent, M., Cubeddu, R., Pifferi, A., Taroni, P., Torricelli, A., 2005. Mealiness detection in apples using time resolved reflectance specroscopy. J. Texture Stud. 36, 439-458.

Valero, C., Ruiz-Altisent, M., Cubeddu, R., Pifferi, A., Taroni, P., Torricelli, A., Valentini, G., Johnson, D.S., Dover, C. J., 2004. Detection of internal quality in kiwi with time-domain diffuse reflecance spectroscopy. Appl. Eng. Agric. 20, 223-230.

Van Beers, R., Aernouts, B., León Gutiérrez, L., Erkinbaev, C., Rutten, K., Schenk, A., Nicolai, B., Saeys, W., 2015. Optimal illumination-detection distance and detector size for predicting Braeburn apple maturity from Vis/NIR laser reflectance measurements. Food Bioprocess Technol. 8, 2123-2136.

Van Beers, R., Aernouts, B., Reis, M.M., Saeys, W., 2017a. Anisotropic light propagation in bovine muscle tissue depends on the initial fiber orientation, muscle type and wavelength. Opt. Express 25, 22082-22095.

Van Beers, R., Aernouts, B., Watté, R., Schenk, A., Nicolaï, B., Saeys, W., 2017b. Effect of maturation on the bulk optical properties of apple skin and cortex in the 500-1850 nm wavelength range. J. Food Eng. 214, 79-89.

Van Beers, R., Kokawa, M., Aernouts, B., Watté, R., De Smet, S., Saeys, W., 2018. Evolution of the bulk optical properties of bovine muscles during wet aging. Meat Sci. 136, 50-58.

van de Hulst, H.C., 1980. Multiple Light Scattering: Tables, Formulas, and Applications. Academic Press, New York.

Vangdal, E., Vanoli, M., Rizzolo, A., Eccher Zerbini, P., Spinelli, L., Torricelli, A., 2012. Detecting internal physiological disorders in stored plums (Prunus domestica L.) by timeresolved reflectance spectroscopy. Acta Hortic. 945, 197-203.

Vanoli, M., Rizzolo, A., Eccher Zerbini, P., Spinelli, L., Torricelli, A., 2009. Nondestructive detection of internal defects in apple fruit by time-resolved reflectance spectroscopy. In: 

Nuenes, C. (Ed.), Environmentally Friendly and Safe Technologies for Quality of Fruits and Vegetables. 20-26, Universidade do Algarve, Portugal.

Vanoli, M., Rizzolo, A., Grassi, M., Farina, A., Pifferi, A., Spinelli, L., Torricelli, A., 2011. Time-resolved reflectance spectroscopy nondestructively reveals structural changes in 'Pink Lady $^{\circledR}$, apples during storage. Procedia Food Sci. 1, 81-89.

Vanoli, M., Rizzolo, A., Grassi, M., Spinelli, L., Zanella, A., Torricelli, A., Zanella, A., Spinelli, L., 2015. Chacterizing apple texture during storage through mechanical, sensory and optical properties. Acta Hortic. 11078, 383-390.

Wang, A., Lu, R., Xie, L., 2017a. A sequential method for measuring the optical properties of two-layer media with spatially-resolved reflectance: simulation study. In: Kim, M., Chao, K., Chin, B.A., (Eds.), Sensing for Agriculture and Food Quality and Safety VIII, SPIE Proceedings 9864, 98640Q, 12pp. SPIE (The International Society for Optical Engineering), Bellingham, WA.

Wang, A., Lu, R., Xie, L., 2017b. Improved algorithm for estimating the optical properties of food products using spatially-resolved diffuse reflectance. J. Food Eng. 212, 1-11.

Wang, L., Jacques, S.L., Zheng, L., 1995. MCML- Monte Carlo modeling of light transport in multi-layered tissues. Comput. Methods Programs Biomed. 47, 131-46.

Wang, L.V., Jacques, S.L., 2000. Source of error in calculation of optical diffuse reflectance from turbid media using diffusion theory. Comput. Methods Programs Biomed. 61, 163-70.

Wang, W., Li, C., 2013. Measurement of the light absorption and scattering properties of onion skin and flesh at $633 \mathrm{~nm}$. Postharvest Biol. Technol. 86, 494-501.

Wang, W., Li, C., Gitaitis, R.D., 2014. Optical properties of healthy and diseased onion tissues in the visible and near-infrared spectral region. Trans. ASABE 57, 1771-1782.

Wang, L.V., Wu, H.I., 2007. Biomedical Optics: Principles and Imaging. John Wiley \& Sons, Hoboken, NJ, USA.

Watté, R., Aernouts, B., Saeys, W., 2016. Monte Carlo modeling of light transfer in food. In: Lu, R. (Ed.), Light Scattering Technology for Food Property, Quality and Safety Assessment CRC Press, Boca Raton, FL, USA, pp 79-109. doi:10.1201/b20220-5

Watté, R., Aernouts, B., Van Beers, R., Herremans E., Ho, Q.T., Verboven, P., Nicolaï, B., Saeys, W., 2015a. Modeling the propagation of light in realistic tissue structures with MMC-fpf: a meshed Monte Carlo method with free phase function. Opt. Express 23, 1746717486.

Watté, R., Aernouts, B., Van Beers, R., Saeys, W., 2015b. Robust metamodel-based inverse estimation of bulk optical properties of turbid media from spatially resolved diffuse reflectance measurements. Opt. Express 5, 27880-27898.

Watté, R., Nguyen Do Trong, N., Aernouts, B., Erkinbaev, C., De Baerdemaeker, J., Nicolaï, B., Saeys, W., 2013. Metamodeling approach for efficient estimation of optical properties of turbid media from spatially resolved diffuse reflectance measurements. Opt. Express 21, 32630-32642.

Xia, J.J., Berg, E.P., Lee, J.W., Yao, G., 2007. Characterizing beef muscles with optical scattering and absorption coefficients in VIS-NIR region. Meat Sci. 75, 78-83.

Xia, J.J., Weaver, A., Gerrard, D.E., Yao, G., 2008. Distribution of optical scattering properties in four beef muscles. Sens. Instr. Food Qual. Safety 2, 75-81.

Zamora-Rojas, E., Aernouts, B., Garrido-Varo, A., Pérez-Marín, D., Guerrero-Ginel, J. E., Saeys, W., 2013. Double integrating sphere measurements for estimating optical properties of pig subcutaneous adipose tissue. Innovative Food Sci. Emerg. Technol., 19, 218-226. 
Zhang, M., Li, C., Fan, S., 2017a. Optical properties of healthy and bruised blueberry tissue in the near-infrared spectral region. ASABE Paper \#1700423. ASABE, St. Joseph, MI, USA.

Zhang, M., Li, C., Yang, F., 2019. Optical properties of blueberry flesh and skin and Monte Carlo multi-layered simulation of light interaction with fruit tissues. Postharvest Biol. Technol. 150, 28-41.

Zhang, S., Wu, X., Zhang, S., Cheng, Q., Tan, Z., 2017b. An effective method to inspect and classify the bruising degree of apples based on the optical properties. Postharvest Biol. Technol. 127, 44-52.

Zhu, Q., He, C., Lu, R., Mendoza, F., Cen, H., 2015. Ripeness evaluation of 'Sun Bright' tomato using optical absorption and scattering properties. Postharvest Biol. Technol. 103, 27-34. 